\title{
UNA CIUDAD, UN SANTO, UNA ORDEN: BOLONIA, Domingo de Caleruega y la ORden de los Frailes Predicadores. EnTRE La VOCACIÓN AL ESTUDIO Y LA CUSTODIA DE LAS SAGRADAS PRENDAS
}

\author{
BEATRICE Borghi \\ Universidad de Bolonia
}

\begin{abstract}
Resumen
En el presente ensayo se ilustrarán los acontecimientos y los símbolos de la devoción a un santo, a una ciudad, a un monumento: Domingo de Caleruega, Bolonia y la basílica y monasterio de los frailes predicadores. No es raro, en Italia, asistir a una integración tan fuerte entre tres diferentes y, al mismo tiempo, complementarias dimensiones de una dinámica histórica. No obstante, en el caso de Bolonia hay algo más: un "cuarto elemento", que alude a la historia y a la función de la Ordo praedicatorum aun precediéndolas más o menos en un siglo. Se trata de la Universidad: el célebre Estudio, valiéndose desde mediados del siglo XII de la previsora legitimación de Barbarroja, y aquellos (en origen y en teoría cualquier convento, porque en cada uno de ellos se estudiaba teología) de los "studentes in sacra pagina".
\end{abstract}

\section{Palabras clave}

Santo Domingo de Caleruega, Orden de los Predicadores, peregrinación, reliquias, inventarios, predicación, universidad.

\begin{abstract}
A saint, a city, a monument. In Italy it is not unusual to meet such a strong integration among three different and yet complementary dimensions of a historical dynamics. However, at a mature and deep state the thing is, if not unique, surely very rare. In the case of Bologna, there is something more: a "fourth element", which recalls the history and the function of the Ordo Predicatorum and yet precedes both of them by more or less a century. This is the university: the famous Studium, which made use since the middle of the $12^{\text {th }}$ century of the far-sighted legitimation of Barbarossa, and those (originally and theoretically any convent, since in all of them theology was studied) of the studentes in sacra pagina.
\end{abstract}

\section{Keywords}

Saint Dominic of Caleruega, Order of Preachers, pilgrimage, relics, inventories, preaching, university.

\section{Riassunto}

Nel presente saggio si illustreranno le vicende e i simboli della devozione ad un santo, ad una città, ad un monumento: Domenico di Caleruega, Bologna e la basilica e monastero dei frati predicatori. Non è infrequente, in Italia, assistere a un'integrazione così forte fra tre differenti ma complementari dimensioni di una dinamica storica. Tuttavia, a uno stato così maturo e profondo la cosa è, se non

* Universidad de Bolonia. E-mail: b.borghi@unibo.it 
unica, certo molto rara. Eppure, nel caso di Bologna, c'è qualcosa di più: un "quarto elemento", che richiama la storia e la funzione dell'Ordo Praedicatorum eppure le precede entrambe di un buon secolo o poco meno. E' l'università: il celebre Studium forte dalla metà del XII secolo della lungimirante legittimazione del Barbarossa, e quelli (in origine e in linea di principio qualunque convento, perché in ciascuno di essi si studiava teologia) degli studentes in sacra pagina.

\section{Parole chiave}

Domenico di Caleruega, Ordine dei Frati Predicatori, pellegrinaggio, reliquie, inventari, predicazione, università.

\section{El asentamiento de los Dominicos en Bolonia}

Preguntarse por qué Domingo ${ }^{1}$ escogió Bolonia como la ciudad idónea para la fundación de su Orden y lugar en el que decidió desarrollar los dos primeros Capítulos, creo que está justificado y bien motivado, si bien una respuesta puede ser difícil, en parte ficticia, y tal vez aún no respaldada totalmente por fuentes documentales. ¿Por qué su decisión recayó en la ciudad del derecho y no, por ejemplo, en la renombrada París o en otras populares ciudades francesas y, más en general, en centros europeos célebres y conocidos?

Para una investigación hagiográfica sobre santo Domingo, el sitio de los Bollandistas contiene las referencias a la Bibliotheca Hagiographica Latina y a las sucesivas ediciones críticas en los «Analecta Bollandiana» $<$ http://www.kbr.be/ socboll/>. A tal propósito, es muy útil también el repertorio puesto a punto por la BAI (Biblioteca Agiografica Italiana), en versión tanto en papel - Biblioteca Agiografica Italiana (BAI). Repertorio dei testi e manoscritti, secoli XIII-XV, a cargo de J. Dalarun, L. Leonardi, y de M.T. Dinale, B. Fedi, G. Frosini et alii, Firenze 2003, 2 vols. - como en formato digital, en CD-rom, con la indicación de las vulgarizaciones italianas, editadas e inéditas. Sobre la creación de la leyenda hagiográfica y la imagen del fundador, los ya clásicos estudios de M.H. Vicaire, St. Dominic and His Times, New York 1964; M.H. Vicaire, Dominique et ses Prêcheurs, Friburg 1977; M.H. Vicaire, Histoire de st. Dominique, 2 vols., Paris $1982^{2}$ (editado también en traducción italiana a cargo de A.V. Ferrua, Roma 1987) y V.D. CARro, Domingo de Guzmán: historia documentada, Madrid 1973, y sobre todo los más recientes y actualizados VL.J. KoudelKa, Dominic, London 1997 y L. CANetTI, L'invenzione della memoria. Il culto e l'immagine di Domenico nella storia dei primi frati Predicatori, Spoleto 1995. Fundamentales también los estudios de S. Tugwell sobre la biografía de Domingo, editados en «Archivum fratrum praedicatorum»: S. Tugwell, Notes on the life of St. Dominic, en «Archivum fratrum praedicatorum», 65 (1995), págs. 5-169; 66 (1996) págs. 5-200; 67 (1997), págs. 27-59; n.s., 28 (1998), págs. 5-116; 73 (2003), págs. 1-141 y las actas del congreso: Domenico di Caleruega e la nascita dell'ordine dei Frati Predicatori (Todi, 10-12 de octubre de 2004), Spoleto (Perugia) 2005; A Dominican bibliography and book of reference, 1216-1992: a list of works in English by and about members of the Order of Friars Preachers, founded by St. Dominic De Guzman (c. 1171-1221) and confirmed by Pope Honorius III, December 22, 1216, a cargo de C.E. Auth, New York 2002. Un sitio muy al día y bastante rico de materiales ordenados críticamente es el coordinado por el historiador holandés Otto Vervaart, con abundantísima bibliografía, en inglés, "History of the Dominican Order", <http://home.kpn.nl/otto.vervaart/dominican_order.htm>. En Salamanca se encuentra el Instituto Histórico Dominicano de la Provincia de España <http://www.dominicos.es/ instituciones/ihd.aspx>, emanación del capítulo provincial ibérico, surgido en 1975. Publica tanto una revista («Archivo Dominicano», véase más adelante en el ítem Revistas), como la colección Monumenta Histórica Iberoamericana de la Orden de Predicadores. Desde 1983, el Instituto ha dado origen al grupo de estudio HIDEVA (Historiadores Dominicos pro Quinto Centenario de la Evangelización de América), que tiene en su haber cinco congresos internacionales de los que se han publicado las Actas, así como la colección Los Dominicos y América (con 10 vols. editados hasta ahora). 
Desde luego, Bolonia en ese momento ya era bien conocida por su Estudio (Studium). Cuando Domingo -durante su viaje de Toulouse a Roma- llega en enero de 1218, la ciudad estaba en pleno fervor político, social, económico y cultural. Debido a su estratégica posición geográfica, Bolonia aparece como una gran encrucijada natural en la que convergen las principales rutas internas de la Italia centro-septentrional y del área euro-mediterránea² .

Tanto en la Plena como en la Baja Edad Media, la ciudad vivió uno de los periodos más prósperos de su historia, marcado por el nacimiento y desarrollo de las magistraturas judiciales y políticas, tendencialmente independientes, que aspiraban al autogobierno ${ }^{3}$ de la ciudad. Tras la destrucción de la fortaleza imperial que tuvo lugar en 1115, nuevas fuerzas se posicionaron en la escena política, participando plenamente en la creación del Concejo.

En este clima particular crecieron las primeras escuelas de derecho, que comenzaron los primeros desarrollos del Estudio. Mientras tanto, la Iglesia boloñesa conseguía emanciparse definitivamente de la de Rávena y sus obispos, por lo general, se mostraron favorables al surgimiento de los organismos municipales ${ }^{4}$.

La sucesiva formación de las universidades de escolares involucró a casas parroquiales y monasterios de la ciudad, que ya en el siglo XII habían dado señales de participación activa en los nuevos progresos y en la promoción cultural: entre ellos, los monasterios de san Esteban, de san Próculo, de santa María de Reno y de san Salvador, que desempeñaron un papel importante también en aquel proceso de organización del Estudio que, desde la original relación privada del consortium entre maestro y escolar, estaba desembocando en formas institucionales oficialmente reconocidas. Dan prueba de ello las numerosas presencias de docentes canonistas boloñeses radicados en varias iglesias, a partir de la casa parroquial de San Pedro, así como la formación de nuevas organizaciones estudiantiles, motivadas por el hecho de que, cada vez más a menudo, los nuevos rectores de las universidades eran clérigos.

La fama de los maestros del Derecho atraía a estudiantes y profesores de toda Europa, pero suscitaba necesariamente la cuestión de la calidad de las mismas enseñanzas, que debían ser tuteladas por una normativa que otorgara un crédito oficial y, por tanto, reconocido, a los currículos de los Magistra. Al mismo tiempo, el fervor religioso de las décadas entre finales del siglo XII y principios del XIII, acompañado por inquietudes personales y colectivas, se expresaba también, y sobre todo, en la predicación por parte de figuras místicas y carismáticas capaces de atraer y catalizar la devoción popular, despertando así la atención de la Iglesia: entre los más conocidos, precisamente, Francisco

2 B. Borghi, R. Dondarin, Bologna. Storia, volti e patrimoni di una comunità millenaria, Bologna 2011. R. Dondarini, Bologna medievale nella storia delle città, Bologna 2000.

3 El propósito era conseguir la autonomía respecto a los demás poderes que gobernaban: los reyes y los señores.

4 A. Vasina, Chiesa e comunità dei fedeli nella Diocesi di Bologna dal XII al XV secolo, en Storia della Chiesa di Bologna, a cargo de Paolo Prodi y Lorenzo Paolini, Bergamo 1997, I, págs. 165-173. 
de Asís, Antonio de Padua y nuestro Domingo de Caleruega ${ }^{5}$. No es de extrañar que las órdenes religiosas vieran en la ciudad universitaria de Bolonia, frecuentada por tantos jóvenes estudiantes, un incentivo extra para llevar a cabo su misión evangélica, en un intento de atraer el interés y generar nuevas adhesiones y vocaciones ${ }^{6}$.

La renovación de la vida ciudadana se manifestó también en la expansión de las actividades económicas y en la presencia en la escena política y social de los nuevos protagonistas del mundo artesano, financiero y comercial. El considerable aumento de la población impulsó una reorganización del tejido urbano involucrando al perímetro de la ciudad, que se fue ampliando progresivamente. Este proceso de urbanización -un fenómeno de larga duración- condujo a la realización de un nuevo recinto amurallado mucho más amplio que el anterior. Así fueron incluidos los monasterios, que habían sido erigidos en las afueras y que ahora se encontraban en el interior de la nueva muralla, y aquellos ciudadanos que, poseyendo terrenos destinados a explotaciones agrarias en los adarves circundantes recién transformados en nuevo espacio urbano, tuvieron la oportunidad de convertirlos en lotes edificables ${ }^{7}$.

En la práctica, la Bolonia de los albores del siglo XIII había de parecerle a Domingo la ciudad ideal para su predicación, dada la presencia de un elevado número de estudiantes -en su mayoría clérigos- que ofrecían un ámbito intelectual privilegiado adonde llevar su mensaje evangelizador. Además, se le presentaba la oportunidad de entrar en contacto con renombrados estudiosos del derecho, que habrían tenido un papel decisivo en otorgar a la organización doctrinal de los frailes dominicos una sólida base jurídica. Fueron probablemente los maestros del Estudio quienes tradujeron el pensamiento del

\footnotetext{
Sobre la relación entre las órdenes franciscana y dominicana y la herencia de los fundadores: K. ELm, Franziskus und Dominikus. Wirkungen und Antriebskräfte zweier Ordensstifter, en «Saeculum. Jahrbuch für Universalgeschichte», 23 (1972), págs. 127-148; P.-M. Gy, Le statut ecclésiologique des Prêcheurs et des Mineurs avant la querelle des Mendiants, en «Revue des sciences philosophiques et théologiques», 59 (1975), págs. 79-88.

6 La importancia de las órdenes mendicantes en el seno de las sedes universitarias de París y Bolonia y, en general, el papel activo de los predicadores, que iban sustituyendo poco a poco al clero secular en las ciudades, constituyó el origen de un amplio conflicto que opuso a dominicos y franciscanos a los seculares. Sobre el tema, véanse D.L. Douie, The Conflict between the Seculars and the Mendicants at the University of Paris in the Thirteenth century, London 1954; Y. Congar, Aspects ecclésiologiques dans la querelle entre Mendiants et séculiers dans la seconde moitié du XIII siècle, en «Archives d'Histoire doctrinaire et littéraire du Moyen Âge», 28 (1961), págs. 35-151; J.-M. DufeIL, Guillaume de Saint-Amour et la polémique universitaire parisienne (1250-1259), Paris 1972; L. PelLegrinI, Mendicanti e parroci: coesistenza e conflitti di due strutture organizzative della 'cura animarum', en Francescanesimo e vita religiosa dei laici nel Duecento. Actas del VIII Congreso de la sociedad de Estudios Franciscanos, Asís, 16-18 de octubre de 1980, Assisi (Perugia) 1981, págs. 129-167; P. SzITTYA, The Antifraternal Tradition in Medieval Literature, Princeton 19862; K. Kerby-Fulton, Hildegard of Bingen and Anti-mendicant Propaganda, en "Traditio», 43 (1987), págs. 386-399.

7 Siguieron dos siglos de otros importantes eventos y cambios: desde el largo y articulado enfrentamiento con Federico Barbarroja, reanudado con el conflicto con su nieto Federico II, y la contemporánea afirmación de las clases emergentes que llevó, en el transcurso del siglo XIII, a la instauración del Concejo llamado "popular" y a los más altos momentos de desarrollo político y económico de la ciudad; hasta el atormentado siglo XIV que, tras la gran crisis de mediados de siglo, vio la recuperación a partir de 1390, celebrada con la construcción de la basílica dedicada al patrón de la ciudad.
} 
fundador de la Orden a su forma legal, ayudándole en la definición de las primeras Constituciones. Por tanto, es de suponer que una de las razones que indujeron a Domingo a convocar las asambleas constituyentes en Bolonia fuera, precisamente, la presencia en San Nicolás de capaces y famosos jurisconsultos.

A esto hay que añadir también que la voluntad de Domingo era contribuir a recomponer el tejido del cristianismo, desgarrado por las protestas y las represiones antiheréticas y que para este fin "debía resultar oportuno concentrarse precisamente en aquellos centros de irradiación que más podían garantizar la propagación en todas las direcciones de los mensajes y criterios de una renovada cohesión"». La activación de una sede de la Orden de Predicadores en Bolonia está muy vinculada a la voluntad claramente expresada por Honorio III, en su carta de junio de 1219, en la que se determinó que el otorgamiento de la licentia docendi estaba supeditado a la autoridad del arcediano de la catedral. En efecto, "confiriendo autoridad y reconocimiento oficial a los estudios boloñeses, se corroboraba también su capacidad de atracción y por consiguiente, la sucesiva de propagación".

Por lo tanto, Domingo invitó a algunos de sus frailes - todos españoles - a reunirse con él en la Pascua de 1219 en el hospicio para peregrinos españoles, en poder de los canónigos de Roncesvalles y situado al norte de la ciudad en la iglesia de Santa María de la Mascarella ${ }^{10}$.

Es probable que, antes de volver a partir hacia Roma, Domingo fuera capaz de conquistar para la vocación a uno de los canónigos y es plausible que entrara en contacto con Ricardo, quien se habría convertido en el primer prior de la comunidad que se instaló

\footnotetext{
R. Dondarini, Insediamenti dei Frati Predicatori a Bologna, en L'origine dell'Ordine dei Predicatori e l'Università di Bologna, a cargo de G. Bertuzzi, Bologna 2006, nota n ${ }^{\circ}$ 7, pág. 235 [Cita del texto original italiano traducida al castellano por Sandra Lavado Martínez].

9 Ibidem [Cita del texto original italiano traducida al castellano por Sandra Lavado Martínez].

10 De acuerdo con lo señalado por algunos escritores boloñeses, los frailes en principio fueron alojados por los monjes benedictinos de san Próculo: se trató más de un alto que de un verdadero asentamiento (cfr. Melloni, Atti e Memorie I II, pág. 42). De las otras Órdenes mendicantes, recordamos que los franciscanos llegaron a Bolonia en 1211, los agustinos en 1247 y los siervos de María en 1261. Todos se establecieron no lejos de los monasterios ciudadanos o cerca de aquellos que habían sido englobados poco tiempo atrás por la tercera muralla. Es evidente que la elección inicial de las órdenes religiosas de instalarse más allá de la muralla llamada "del Mille", era debida esencialmente a motivos prácticos: el menor coste de la tierra, la posibilidad de elegir un área adecuada a sus necesidades y ampliable en el futuro, la facilidad de los abastecimientos y la posibilidad de asegurarse la protección de la guardia de la ciudad. Las palabras del agustino Jacobo de Vitry a propósito de las características de los frailes predicadores recién asentados en Bolonia son emblemáticas: «ellos militan en el campamento del rey eterno y... le sirven con humildad. Además, ellos son estudiantes de la Universidad de Bolonia y se reúnen cada día por divina inspiración, escuchando lecciones sobre las Sagradas Escrituras dictadas por uno de ellos. Lo que han aprendido diligentemente, lo transmiten después a los fieles en los días festivos con las predicaciones». The Historia Occidentalis of Jacques de Vitry, Friburg 1972, XXVII, pág. 142. Cfr. R. DondarinI, Insediamenti dei Frati Predicatori a Bologna, en L'origine dell'Ordine dei ..., cit., págs. 230-252, en part. pág. 231 y 233. Dondarins, Insediamenti dei Frati Predicatori a Bologna, en L'origine dell'Ordine dei ..., cit., págs. 230-252, en part. pág. 231 y 233 [Cita del texto original italiano traducida al castellano por Sandra Lavado Martínez].
} 
luego en San Nicolás de las Viñas. En Roma, Domingo se reunió en varias ocasiones con el cardenal Hugolino, el futuro papa Gregorio IX, con quien es razonable creer que desarrollara las sucesivas estrategias ${ }^{11}$.

A instancias del mismo Domingo, fray Domingo de España y fray Miguel de Ucero llegaron a Bolonia, seguidos por los frailes Bertrán de Garrigues, Juan de Navarra y, después de algún tiempo, llegaron también fray Cristián y un anónimo fraile converso. De estos frailes sabemos realmente muy poco. Permanecerán en la ciudad del Derecho fray Cristián, el converso y fray Ricardo. Pero las cosas no debieron ir bien. A pesar de la vida penitente y austera que conducían, los ciudadanos no fueron conquistados por su fervorosa forma de vida ${ }^{12}$.

Pronto apareció en escena un hombre de extraordinario carisma que daría un viraje ejemplar a la fundación de la Orden: el maestro jurista Reginaldo, deán de San Aniano de Orleáns, profesor de derecho canónico en París, de regreso de una peregrinación a Tierra Santa, llega a Bolonia el 21 de diciembre de 1218 como vicario de Domingo. Él conquistaría a los jóvenes con el ideal de caridad y de vida del santo y comprobaría que Bolonia era la ciudad adecuada para acoger la fundación de la Orden.

Las cofradías laicas, y en particular el movimiento del Aleluya de 1233, habrían consolidado la labor apostólica de los predicadores, que acogieron en su seno esas manifestaciones de devoción popular consideradas por la Iglesia como formas heterodoxas de religiosidad y, consiguientemente, las reordenaron dentro de la ortodoxia ${ }^{13}$.

\footnotetext{
11 Sobre los documentos papales relativos a los predicadores, redactados mientras Domingo estaba presente en la curia: N.R.P. ZuTshi, Letters of Pope Honorius III concerning the Order of Preachers, en Pope, Church and City. Essays in Honour of Brenda M. Bolton, a cargo de F. Andrews, C. Egger, C.M. Rousseau, Leiden-Boston 2004, págs. 269-286, y también N.R.P. Zutshi, Pope Honorius III's Gratiarum omnium and the Beginnings of the Dominican Order, en 'Omnia disce'. Medieval Studies in Memory of Leonard E. Boyle, OP, a cargo de A.J. Duggan, J. Greatrex, B. Bolton, Farnham 2004, págs. 199-210.

12 Domingo regresa a Bolonia y se encuentra con el Obispo Enrique de Fratta para entregarle las cartas comendaticias.

13 Sobre el movimiento del Aleluya, se recomiendan las siguientes obras: V. Fumagalli, In margine all'Alleluja del 1233, en «Bollettino dell'Istituto Storico Italiano per il Medio Evo e Archivio Muratoriano», 80 (1968), págs. 257-272; ID., Uomini e paesaggi medievali, Bologna 1989, págs. 143-159, con el título Motivi naturalistici e aspirazione alla pace: l'Alleluja' del 1233; M.-H. VICAIRE, Geschichte des heiligen Dominicus, II, Freiburg-Basel-Wien 1963, págs. 255 y sig. Cfr: M. GAZzINI, In margine all'Alleluia del 1233: la Milizia di Gesù Cristo di Parma (1233-1261), en Uno storico e un territorio: Vito Fumagalli e l'Emilia occidentale nel Medioevo, a cargo de R. Greci y D. Romagnoli, Bologna 2005, págs. 235-259; C. Sutter, Giovanni da Vicenza e l'Alleluia del 1233, (Freiburg 1981), tr. it. a cargo de M. G. y O. Da Schio Vicenza 1900; A. VAuchez, Une campagne de pacification en Lombardie autour de 1233. L'action politique des Ordres Mendiants d'apres la réforme des status communaux et les accords de paix, "École Française de Rome: Mélanges d'archéologie et d'histoire", 78 (1966), págs. 519-549 (después en Idem, Religion et société dans l'Occident medieval, Torino 1980, págs. 503-549; y ahora traducido en Idem, Ordini mendicanti e società italiana. XIII-XV secolo, Milano 1990, págs. 121-161, con el título Una campagna di pacificazione in Lombardia verso il 1233. L'azione politica degli Ordini Mendicanti nella riforma degli statuti comunali e gli accordi di pace); F. BARocell, L'Alleluia di Parma del 1233. Il rito, l'immagine, la città, en "Aurea Parma", 67-68 (1983-1984), págs. 232-256; D.A. Brown, The Alleluia. A Thirteen Century Peace Movement, en «Archivum Fratrum Praedicatorum», 81 (1988), págs. 3-16; A. Thомpson, Predicatori e politica nell'Italia del XIII secolo. La 'Grande Devozione' del 1233, (Oxford 1992), Milano 1996.
} 


\section{Una iglesia dedicada a Santo Domingo: de Santa María de la Mascarella a la iglesia y casa parroquial de San Nicolás de las Viñas}

Si Bolonia se presentó para Domingo como la ciudad ideal para difundir la palabra de Dios y para preservar la doctrina cristiana contra la herejía, la primitiva sede en la que fueron acogidos los compañeros de Domingo no resultó ser adecuada para las funciones y actividades que emprendieron. Desde el inicial y provisional asentamiento de los predicadores, la iglesia de Santa María de la Mascarella resultó para los frailes "demasiado lejana e incómoda" para su misión de divulgar la fe, al estar lejos del núcleo vital de la ciudad. Su decisión de trasladarse a la collación de San Nicolás de las Viñas ${ }^{14}$-también conocida por el nombre de San Nicolás de Braida- fue por lo tanto el resultado de una cuidadosa y minuciosa reflexión que les indujo un año después de su llegada ${ }^{15}$, el 29 de marzo de 1219, a tomar posesión de la iglesia de San Nicolás de las Viñas. El edificio sagrado, datado probablemente de la segunda mitad del siglo XII ${ }^{16}$, ubicado en el barrio

14 Posteriormente esta collación asumirá la denominación de collación de Santo Domingo. Erróneamente, Guidicini había identificado el área con el nombre de "San Bartolomé de las Viñas".

15 No hay evidencias escritas que acrediten la fecha de construcción de la iglesia de san Nicolás. El primer rastro de su presencia data del 1198 (L. AlberTI, Historie di Bologna. Historiae urbium et regionum Italiae rariores, XLIV 1541, reimpresión anastática, Bologna 1970, I, L, VIII, 805). Del primer asentamiento de los frailes predicadores en Bolonia y de su ubicación más allá de las murallas de la ciudad hace una breve mención también Jacobo de Vitry: «Fuera de la ciudad de Bolonia, no muy lejos de ella, hay una Orden de canónigos regulares, gratos a Dios y a los hombres»: The Historia Occidentalis of Jacques de Vitry, op. cit., pág. 142 [Cita del texto original italiano traducida al castellano por Sandra Lavado Martínez]. En el año 1198 Pascipovero fue sepultado en San Nicolás de las Viñas; una lápida sepulcral atribuida a la familia puede verse ahora en el claustro de Santo Domingo, conocido como "de los muertos". Pero según Gelichi y Rinaldi, las lápidas conservadas en el convento de Santo Domingo no resultan anteriores al siglo XIV, ni tampoco la referida a los Pascipovero. S. Gelichi, R. Rinaldi, Il Sepoltuario del 1291, en Archeologia medievale ..., cit., $\mathrm{n}^{\circ} 23$, pág. 107. De opinión diferente A. Radigonda, Il Chiostro monumentale ..., cit., págs. 47-48. Según Francesco Valeri Malaguzzi, la iglesia recibida por los frailes se presentaba con la fachada girada hacia el oeste de las capillas de Santo Domingo y de la Virgen del Rosario, y se remataba en altura con las dos cornisas, existentes aún en parte (La chiesa e il convento di San Domenico a Bologna secondo nuove ricerche, en «Repertorium für Kunstwissenschaft», Berlin und Stuttgart 1897, pág. 175). Sobre la topografía urbana en Bolonia se puede consultar R. Rinaldi, Dalla chiesa di S. Nicolò delle Vigne al convento di S. Domenico. Società e topografie urbane a Bologna, en ID., Dalla via Emilia al Po. Il disegno del territorio e i segni del popolamento (secc. VIII-XIV), Bologna 2005, págs. 223-250.

16 Como ha señalado Rinaldi (cit.), el viñedo de san Próculo entre finales del siglo XII y durante todo el siglo XIII "sufrió progresivos fraccionamientos y parcelaciones, que incrementaron la actividad de construcción y acabaron por reducir drásticamente la superficie originaria de la propiedad. Mientras tanto, también la adyacente collación de San Nicolás de las Viñas - que asumió después la denominación de collación Sancti Dominici - registraba en su ordenación original incisivas modificaciones”, pág. 229 [Cita del texto original italiano traducida al castellano por Sandra Lavado Martínez]. El 18 de septiembre de 1232, los monjes de San Próculo otorgan la concesión a los frailes predicadores para que construyan un conducto en su viñedo a fin de llevar el agua del canal de Savena hasta el convento y el huerto (Archivio di Stato, fondo S. Domenico, 249/7583). El instrumento notarial está conservado en el "vidimus" auténtico del obispo boloñés Ottaviano Ubaldini II (1260-1295), también en V. Alce, Documenti sul convento di S. Domenico in Bologna, cit., págs. 24-26. A propósito del viñedo de San Próculo y de las fases de parcelación, consúltense las siguientes obras: M. Giansante, Il quartiere bolognese di Porta Procola alla fine del Duecento. Aspetti economici e sociali nell'estimo del 1296-97, en «Il Carrobbio», XI (1985), págs. 123-141; A. I. PINI, Gestione 
(collación) de San Próculo, se ponía bajo el patrocinio de la influyente familia de los Carbonesi, partidaria de los intereses imperiales contra la política papal.

Pedro de Lovello, exponente de la familia y abuelo de Diana de Andaló ${ }^{17}$ Lovello -que ya se ha recordado en varias ocasiones como la fundadora del dominico monasterio femenino de Santa Inés- vendió a los frailes predicadores una parcela de terreno de $4.160 \mathrm{~m}^{2}$ que se extendía hasta el foso defensivo ${ }^{18}$, apenas dentro del recinto de los "Torresotti" y en el que se ubicaba la iglesia de San Nicolás ${ }^{19}$.

economica, viticoltura ed olivicoltura nell'azienda agraria del monastero bolognese di S. Procolo alla fine del '200, en Id., Campagne bolognesi. Le radici agrarie di una metropoli medievale, Bologna 1993, págs. 93-135.

17 El nombre "Andaló" es el apodo dado a Andrés Lovello. Sobre Diana de Andaló (1200 aprox.-1236) y el monasterio dominicano de Santa Inés en Bolonia, consúltense las siguientes obras: H. M. Cormier, Vita delle Beate Diana d'Andalò, Cecilia e Amata, Roma 1892; Chroniques du monastère de San Sisto et de San Domenico e Sisto à Rome, a cargo de J.J. Berthier, II, Levanto 1920, págs. 585-588; Beati Iordani de Saxonia Epistulae, a cargo de A. Walz, en Monumenta Ord. Fr. Praed. histarica, XXIII (1951); IoRdANI DE SAXonia, Opera quae extant, a cargo de J. J. Berthier, Freiburg 1891; Acta Sanctorum, Iunii, II, Antverpiae 1698, págs. 363-368; G. B. Melloni, Atti e Memorie degli uomini illustri in santità nati o morti in Bologna, I, Bologna 1773, págs. 194-255, 363-389; Confirmationis cultus immemorabilis simul ac concessionis et approbationis commemorationis servarum Dei Caeciliae et Amatae auae beatae nuncupantur ad iungendae Officio, Missae et Elogio in Martyrologio in honorem b. Dianae de Andalo, Roma 1890; N. Malvezzi, Diana d'Andalò, Bologna 1894; D.A. Mortier, Histoire des maîtres généraux de l'Ordre des Frères Prêcheurs, I, Paris 1903, pp. 94-106, 138-170; H. Сн. ScheEBen, Beiträge zur Geschichte Jordans v. Sachsen, en Quellen u. Forschungen zur Gesch. d. domenikaner Ordens in Deutsch, XXXV, Leipzig 1938, págs. 16, 18, 46, 55, 74 5-, 83-95; A. WaLz, Intorno alle lettere del b. Giordano di Sassonia, en «Angelicum», XXVI (1949), págs. 143 164, 218-232; Encicl. cattolica, IV, col. 1552; Dictionnaire d'Histoire et de Géogr. Ecclésiastique, XIV, col. 379 s.; M.G. CAmbria, Il monastero domenicano di S. Agnese in Bologna. Storia e documenti, Bologna 1973.

18 El área en que los frailes se asentaron fue erróneamente considerada por Jacobo de Vitry "extra civitatem Bononie, non longe ab ea". Seguramente la zona, por sus características típicamente agrícolas (y por tanto, poco urbanizada) y por su posición orientada hacia el lecho del torrente Aposa, debía parecer al agustino una superficie ubicada más allá de las muros de la ciudad. The Historia Occidentalis of Jacques de Vitry, cit. Se señala que la denominación "de las Viñas" ha de relacionarse precisamente con el área agrícola y los viñedos que la distinguían. Terrenos dedicados en primer lugar a la agricultura y después, a partir de la segunda mitad del siglo XII, parcelados en terrenos edificables.

19 ASBo, Demaniale, S. Domenico 120/7454, $\mathrm{n}^{\circ}$ 1. Cfr. Koudelka, Monumenta diplomatica Sancti Dominici, cit., $\mathrm{n}^{\circ}$ 97, págs. 99-102. El terreno comprado por los dominicos abarcaba, por tanto, superficies agrícolas (entre ellas huertos y viñedos) y superficies edificadas. Sólo en un segundo momento, sucesivo a la compra del terreno, las viviendas presentes en dichos terrenos pasaron a ser de propiedad de los frailes “...según una costumbre extendida, las áreas urbanas parceladas eran alquiladas por los propietarios a personas o familias que hacían erigir, corriendo con los gastos, edificios de viviendas de los que se convertían en poseedores a todos los efectos. Por esto los Predicadores, tras haber comprado el terreno a Pedro, se dirigieron a sus inquilinos..." (Rinaldi, Dalla chiesa di S. Nicolò delle Vigne..., cit., pág. 234) [Cita del texto original italiano traducida al castellano por Sandra Lavado Martínez]. Según Masini (A. MASINI, Bologna perlustrata, Bologna 1666, pág. 118), Diana donó una casita cerca del lugar en el que instalaron los frailes predicadores. Sobre los contratos de compra de los dominicos de los locales limítrofes al área de San Nicolás de las Viñas, consúltense los documentos publicados por padre Koudelka en el volumen XXV de los Monumenta Ordinis Fratrum Praedicatorum Historica, cit. También Guidicini (Cose notabili della città di Bologna, Bologna 1868-1873, vol. II, pág. 7) indica otras parcelas de terreno compradas por los frailes y no recordadas por Venturino Alce. Pero como se ha dicho, Guidicini cometió el error de identificar San Nicolás de las Viñas con San Bartolomé de las Viñas, dos iglesias distintas, si bien se encontraban en la 
El sacerdote que atendía la pequeña iglesia, Rodolfo de Faenza, estuvo dispuesto a cederla a los frailes ${ }^{20}$, con transmisión confirmada por el mismo obispo de Bolonia. Pero el traspaso definitivo tuvo lugar gracias a la influencia ejercida por Diana de Andaló sobre su reacio abuelo Pedro de Lovello ${ }^{21}$, que permaneció hasta su muerte patrono de la iglesia. Entre 1219 y 1240, los religiosos adquirieron todos los terrenos del área pertenecientes a las distintas ramas de la familia de los Carbonesi, tomando posesión de un área de más de 31.500 metros cuadrados ${ }^{22}$, limitada al norte por una serie de casas bien alineadas, al sur por las murallas del siglo XI, al este por el lecho del torrente Aposa y al oeste por la calle pública creada sobre el foso romano colmatado de tierra. Con el fin de facilitar la mudanza de los frailes desde Santa María de la Mascarella, fray Rodolfo se apresuró a ampliar la pequeña iglesia de San Nicolás con la construcción de las celdas. Según se informa en el Vitae Fratrum, la llegada de los frailes a San Nicolás habría sido anunciada por una serie de premoniciones contadas por Rodolfo de Faenza, Juan de Bolonia y fray Claro ${ }^{23}$.

Los frailes se trasladaron a la nueva sede, probablemente a principios de abril ${ }^{24}$; fray Ricardo, superior de la iglesia de Santa María de la Mascarella, fue el primer prior de la comunidad ${ }^{25}$. Cuando, en agosto del mismo año, Domingo llegó a Bolonia, encontró una comunidad numerosa, que había captado la simpatía de muchos fieles - gracias también a las dotes de predicación de Reginaldo y al ejemplar estilo de vida de los frailes pre-

misma área, error oportunamente señalado y corregido por Breventani. Cfr. V. ALCE, Documenti sul convento di San Domenico in Bologna dal 1221 al 1251, en «Archivum fratrum praedicatorum», XLII (1972).

20 Rodolfo de Faenza estaba particularmente ligado a Domingo porque "durante todo el tiempo que fray Domingo residió en Bolonia, vivió a su lado en la iglesia durante el Oficio, en el dormitorio, en el refectorio, de día y de noche, dado que era el ecónomo de la comunidad" (en Acta canonizationis, $\mathrm{n}^{\circ}, 30-34$ ) [Cita del texto original italiano traducida al castellano por Sandra Lavado Martínez]. El encargo le fue encomendado por Reginaldo, vicario de Domingo. Mientras tanto, Rodolfo ingresó en la Orden y, gracias a su amistad con el obispo de Ostia, el cardenal Hugolino, que estaba de paso en Bolonia, obtuvo la aprobación del obispo de la ciudad para regularizar el traspaso efectivo de la pequeña iglesia de San Nicolás a los frailes predicadores. El acto de compraventa del terreno, de unos $2.310 \mathrm{~m}^{2}$ de extensión, data del 14 de marzo de 1219 (Documenta diplomatica, $\mathrm{n}^{\circ}$ 97), en el que Pedro de Lovello vende a Reginaldo -que compra en nombre de los frailes-, la iglesia de San Nicolás.

21 De la venta, Pedro obtuvo la considerable suma de 1.700 liras. ASBo, S. Domenico 120/7454, n 1 , $125 / 7459, \mathrm{n}^{\circ} 1$. Cfr. M. FanTI, Il ritrovato originale del contratto fra S. Domenico e Pietro Lovello del 7 giugno 1221, en «Archivum fratrum praedicatorum», XXXVI (1966), págs. 389-394.

22 Monumenta diplomatica, 126, 127.

23 Vitae fratrum, págs. 20-21. En las Vitae, Rodolfo de Faenza relata el prodigio de una señora pía que, rezando de rodillas en la viña, había afirmado que a aquel lugar habrían llegado personas "para las que se habría iluminado el mundo" (pág. 20). Juan de Bolonia cuenta que algunos hombres que estaban trabajando en la viña, dijeron haber visto una luz en el lugar donde llegarían los frailes. Por último, fray Claro cuenta que un día, su padre, pasando al lado de San Nicolás, afirmó que en aquel lugar se habían escuchado "frecuentemente cantos angelicales, lo cual es señal de grandes cosas para el futuro" (págs. 20-21) [Citas del texto original italiano traducidas al castellano por Sandra Lavado Martínez].

24 Aquel año la Pascua se celebró el 7 de abril.

25 A pocos días del asentamiento en San Nicolás, son varios los nuevos adeptos a la Orden. Las Vitae fratrum mencionan al caballero de la corte imperial Tancredi y a un anónimo joven estudiante. En ambos casos es la Virgen María quien les solicita que entren en la comunidad. 
dicadores- y que podía preciarse de contar con maestros en derecho, en filosofía y con varios sacerdotes. Todos acudían a escuchar a Domingo, que se dedicó a hacer crecer "con admoniciones y ejemplos la aún tierna infancia de aquella joven plantación"26; las iglesias estaban abarrotadas y resultaban insuficientes para dar cabida a tanta gente. Así, las plazas se convirtieron en los lugares más adecuados para acoger a los devotos y a los laicos; especialmente a los jóvenes estudiantes universitarios. Consejero y "consolador", Domingo sabía utilizar "palabras tan conmovedoras que muy frecuentemente se emocionaba hasta las lágrimas y hacía llorar al auditorio" 27.

El 18 de mayo de 1220 se celebró el primer Capítulo general y la comunidad podía contar con la presencia de unos treinta religiosos. La edificación del convento, después de sólo pocos meses del asentamiento de los frailes en la pequeña iglesia de San Nicolás, se hallaba en un estado avanzado, tanto que, al año siguiente, se habrían construido el claustro y la sala capitular ${ }^{28}$. Con ocasión del Capítulo General, Diana de Andaló pidió a Domingo la construcción del convento femenino, pero la decisión se pospuso a la espera de encontrar un lugar idóneo y grato al obispo.

Para algunos estudiosos, 1221 marcó el inicio de la ampliación del primer núcleo de la iglesia de San Nicolás de las Viñas; por el contrario, para otros se trató de una demolición total del edificio para la construcción de un nuevo complejo ${ }^{29}$. Recordemos también que en ese año, el 13 de enero, fray Pablo, "priore atque rectore collegii sive universitatis ecclesie Beati Nicolai de Braida de Ordine Predicatorum", saldó la deuda de 600 liras que había contraído con Pedro de Lovello, dándole la suma de 300 liras $^{30}$; el 7 de junio de 1221, el mismo Domingo compró a Pedro tres tornature [unidad de medida agraria] de tierra al este de la parcela recibida de Reginaldo de Orleáns ${ }^{31}$. Lo que es seguro es que en 1233, la nueva estructura tenía que estar casi terminada, ya que se podía acceder a ella para la solemne traslación del cuerpo de Domingo al nuevo lugar que habría recibido sus restos.

\footnotetext{
26 JoRdÁn De SAJONIA, Libellus, cit., 60, trad. it., cit., pág. 136. Domingo predica un sermón casi cada día o al menos una exhortación a los frailes (Acta canonizationis, 6). [Cita del texto original italiano traducida al castellano por Sandra Lavado Martínez].

27 Estas palabras son de fray Esteban: en Acta canonizationis, 37, 47.

28 El mismo Domingo participó en la compra de un terreno de $6.240 \mathrm{~m}^{2}$ (Monumenta diplomatica, 174) Se recuerda que durante el segundo Capítulo General de la Orden, celebrado en Bolonia el 30 de mayo de 1221, se había procedido a dividir las competencias territoriales de la Orden en ocho provincias. A fray Jordán de Sajonia se le confió la provincia de Lombardía, que preveía la presencia de la iglesia - gobernada por fray Ventura de Verona - y del convento de Bolonia.

29 Cfr. I.B. SupINo, L'architettura sacra in Bologna nei secoli XIII e XIV, Bologna 1909; ID., L'arte nelle chiese di Bologna (secc. VIII-XVI), 2 vols., Bologna 1932-1938; R. GianninI, Vita quotidiana ed osservanza della regola in un registro trecentesco di S. Domenico di Bologna, en Miscellanea Gilles Gérard Meèrsseman, Padova 1970, vol. II, págs. 313-342; T. Alfonsi, La chiesa di S. Niccolò delle Vigne a Bologna dal 1221 al 1251, «Rosario e Memorie Domenicane», 1915, pág. 321. Las primeras intervenciones de ampliación se centraron en erigir el cuerpo de algunas celdas.

30 ASBo, Demaniale, San Domenico 120/7454. Cfr. Annali, p. 2; MOPH 25 pp. 141-142.

31 ASBo, Demaniale, San Domenico, 125/7459 n 1a; Bolle e brevi riflettenti gli eretici, Biblioteca Municipal del Archiginnasio, B. 3695; MOPH 25, págs. 172-17.
} 
Derribados los edificios que se encontraban en el terreno hortícola y prácticamente también la misma iglesia de San Nicolás de las Viñas, entre 1228 y 1240 los frailes predicadores erigieron - gracias también a la compra de tierras y viviendas ${ }^{32}$ - el nuevo edificio y convento con un proyecto arquitectónico preciso y un plan de construcción que respondía plenamente a los ideales de la Orden, de vida apostólica y de organización interna de los mismos frailes.

El 24 de mayo de 1233, la iglesia estaba lista para acoger a más de trescientos religiosos llegados a Bolonia para asistir a la traslación del cuerpo de santo Domingo ${ }^{33}$. La iglesia estaba terminada y la atención se dirigía ahora, no sin gravosos problemas de índole económica, a completar el convento ${ }^{34}$. Las obras de ampliación afectaron a la sacristía, la sala capitular, el dormitorio, el lugar de depósito - donde estaba el espacio destinado a la conservación de los libros de la sacristía, el armarium -, el libratorio, el cabildo de los novicios y profesos, el refectorio, los locales de las escuelas de estudio teológico, la enfermería, la casa de huéspedes ${ }^{35}$. El espacio que rodeaba el cuadrilátero del primer claustro, llamado con el nombre del fundador de la Orden (también conocido como claustro de los muertos) y que incluía la iglesia de Santo Domingo con el coro, el dormitorio, el cabildo, la biblioteca, el refectorio y el granero, fue delimitado por el muro insuperable de la clausura.

Las obras de ampliación terminaron en 1240 con la construcción de la sobria portada románica. Desde entonces, la Basílica de Santo Domingo se convirtió en el prototipo de muchas iglesias dominicas en el mundo y se enriqueció con el tiempo con espléndidas obras de arte. De hecho, fue con motivo de la consagración de la iglesia, acaecida el 17 de octubre de 1251 por obra del Papa Inocencio IV, que fue exhibido el famoso crucifijo de Giunta Pisano (1250 aprox.) que aún se conserva en la capilla de San Miguel Arcángel ${ }^{36}$.

32 AFP, 42 (1972), págs. 16-22; 39-42

33 La presencia del cuerpo del fundador de la Orden habría sugerido, pocos años después, en 1235, que se dedicara el templo cristiano a "santo Domingo", denominación que se extendería también a la collación (“Sancti Dominici”). MOPH XVI, pág. 132; AFP, 42 (1972), pág. 38; AFP, 42 (1972), págs. 41-42.

34 El área del convento abarca el espacio actual ubicado entre piazza San Domenico, via Garibaldi, via Vascelli, piazza del Tribunale, via San Domenico, la iglesia homónima y el huerto de los frailes predicadores. Fueron muchos los contratos de compra de terrenos estipulados por el convento. Necesaria para asegurar la "clausura" conventual fue también la compra de los terrenos de huerto colindantes con el torrente Aposa, desde Cestello hasta la iglesia de San Nicolás. Cfr. AFP, 42 (1972), págs. 26-27. Los gastos que había de afrontar la comunidad de religiosos eran más bien onerosos, tanto es así que los frailes se vieron «obligados a recurrir a préstamos de dinero para hacer frente a los gastos de construcción... incluso a los "mercaderes" de dinero». A. D’Амato, I Domenicani a Bologna, cit., I vol., pág. 113, véase la nota 31. [Cita del texto original italiano traducida al castellano por Sandra Lavado Martínez]. Los usureros fueron exhortados a arrepentirse y a devolver las cantidades, que fueron destinadas a las obras de ampliación de la iglesia y del convento. AFP, 42 (1972), págs. 8, 17, 38, 39.

35 En el siglo XIII, el convento disponía de otros locales, además de los recién mencionados: entre éstos el guardarropa, la cantina, la "canova" (lugar utilizado para conservar el vino y la comida), el horno, la leñera, un espacio donde los frailes practicaban la tonsura monástica, la "calzolaria".

36 El 17 de ottobre de 1251, el Papa, los obispos de Bolonia, Imola, Forlí, Rávena y Chioggia concedieron indulgencias para el día de la consagración de la iglesia de Santo Domingo. Pocos años después, en 1255, 
En 1233, mientras los trabajos de construcción de la basílica y del convento estaban en marcha, los restos del cuerpo de santo Domingo fueron colocados en una caja de ciprés, a su vez cerrada en un sencillo sarcófago de mármol y colocado "sobre tierra" detrás del altar de una capilla lateral de la nave derecha. Con el fin de hacer visible el sepulcro a los fieles, que llegaban cada vez más numerosos después de la canonización del santo acaecida el 13 de julio de 1234, en 1267 el cuerpo fue colocado en un monumento de mármol más insigne y digno, decorado por Nicola Pisano y sus alumnos. Los restos del cuerpo del santo finalmente podían ser admirados y contemplados por todos los peregrinos y fieles que llegaban, porque el sarcófago descansaba sobre seis columnas colocadas en un pedestal. Santo Domingo se convirtió en el santo patrón de la ciudad ${ }^{37}$. La afirmación de su culto se detecta en su reconocimiento público como defensor de la ciudad de Bolonia.

Mientras tanto, algunos de los gremios más potentes se convierten en los nuevos protagonistas de la vida política y económica ciudadana. Los mercaderes y cambistas, de hecho, entraron a formar parte de los órganos de gobierno y la ciudad fue clasificada en distritos administrativos: los cuatro barrios, divididos en "capellanías" o parroquias confiadas a un "ministerial". Los exponentes populares, aunque expulsados del gobierno por los aristócratas de 1220 a 1227, pasaron a formar parte del nuevo Consejo General Municipal en 1228 y el órgano de la Curia del Potestad fue sustituido por el Colegio de los Ancianos (con representantes de las sociedades populares) y de los Cónsules (con delegados de cambistas y mercaderes). Precisamente este fermento ciudadano, unido a la inestabilidad general, debió de inducir a la Orden de Predicadores a no dispersar la devoción popular al santo fundador, atestiguada desde el comienzo de la predicación de Domingo y acrecentada aún más después de su muerte. Es en este contexto en el que se debe interpretar el encuentro entre

el papa Alejandro V invitó al abad y al Capítulo general de la Orden cisterciense a celebrar la fiesta del fundador de la Orden de predicadores y de san Pedro Mártir. N 1266, Clemente IV conminará la misma celebración también a los obispos de Portugal. Cfr. Annali, págs. 21-22; G. Melloni, Atti, o memorie degli uomini illustri in santità nati, o morti a Bologna, Bologna 1788, cl. 1, vol. 2, págs. 218-219. Cherubino Ghirardacci, en su Historia di Bologna, del año 1251, a propósito de la consagración de la iglesia de Santo Domingo por obra de Inocencio IV, nos informa de que el papa concedió "perpetua indulgencia en el día de tales consagraciones (las iglesias de Santo Domingo y de San Francisco). [Cita del texto original italiano traducida al castellano por Sandra Lavado Martínez]. Pero la estima hacia los dos frailes por parte de la ciudad se acrecentó de tal manera que fueron considerados tutores de Bolonia, «Li Frati dell'uno, \& 1'altro ordine cominciarono a salire in tanta reputazione appresso la Città, che sovente in loro si confidavano i segreti della Città, \& erano ammessi per testimoni alle Tavole, \& attioni d'importanza» (vol. I, pág. 181). 37 En los Annali (p. 247), se recuerda que la «Comunità di Bologna accettato il padre san Domenico per Confaloniere, Difensore, e vero Patrone della città risolve di celebrare con ogni pompa con intervento delle arti trombe etc il giorno della sua festa cioè li 5 agosto di offerire in tal giorno per il pubblico depositario lire $100 \mathrm{al}$ convento, e di obbligare il podestà a congregrare tre giorni innanzi il gonfaloniere, le compagnie de stendardi etc». Melloni, en su Atti, o memorie degli uomini illustri in santità nati, o morti a Bologna (vol. 2, págs. 219-221) refiere en nota que lo mencionado arriba es recordado también en los estatutos municipales de los años 1313, 1314, 1335 y siguientes. 
Juan de Vicenza ${ }^{38}$, el Papa Gregorio IX, Enrique de Fratta, obispo de Bolonia, y los representantes de la Orden y la cúpula del Estudio, preludio de la canonización de 1234. En señal de este diseño de inversión de la Iglesia en la devoción popular a los nuevos santos, el papa Inocencio IV consagró en 1251 la iglesia terminada de Santo Domingo y la de San Francisco.

En 1264, los frailes predicadores enviaron una petición a los órganos municipales porque "no tienen terreno suficiente que cultivar para producir la verdura que cubra sus necesidades; además, su edificio es muy inseguro a causa del foso que afecta a la enfermería. Por tanto, solicitan que se les conceda el terreno del foso municipal, que pasa cerca de la enfermería y sobre el terreno de su propiedad, para poder cerrarlo y allanarlo, dejando intacta la calle que discurre al lado"39. El Concejo aceptó la petición: el tramo del foso fue cubierto; en 1288 aprobará otra petición de los frailes, la de cerrar con un muro el terreno, destinado a huerto, que cubría el mismo foso ${ }^{40}$. La posesión de terrenos y casas intramuros y extramuros del inmenso patrimonio inmobiliario de los frailes boloñeses se incrementó con el tiempo con nuevas adquisiciones, gracias principalmente a nuevas donaciones y legados testamentarios de fieles ciudadanos que quisieron para su sepultura el área de cementerio anexa al convento ${ }^{41}$; esto se hizo especialmente significativo después de sólo unas décadas desde la llegada de los dominicos por el progresivo abandono de su rechazo inicial a poseer bienes ${ }^{42}$. En este

38 Sobre la figura de Juan de Vicenza y sus relaciones con la Orden de los frailes predicadores, consúltese: M. Rainini, Giovanni da Vicenza, Bologna e l'Ordine dei Predicatori, en L'origine dell'Ordine dei Predicatori e l’Università di Bologna, cit., Bologna 2006, págs. 146-175.

39 AFP, 42 (1972), págs. 43-44 [Cita del texto original italiano traducida al castellano por Sandra Lavado Martínez].

40 El 26 de febrero de 1264, el Consejo municipal de Bolonia concedió a los frailes dominicos la posibilidad de utilizar todo el foso, allanarlo y cerrarlo, dejando libre la calle pública, para agrandar su huerto y beneficiar a la enfermería. El 18 de abril de 1288, el mismo Consejo concedió a la comunidad de religiosos cerrar el foso con un muro, colmado de tierra, que pasase sobre el terreno de la enfermería y que se extendiese desde el puente del Aposa hasta el parapeto del otro puente, cercano a la calle Mirasole. Archivio conventuale di San Domenico, CI a sec. XIII, Con. n. 3, membranaceo. En V. Alce, Documenti sul convento di S. Domenico in Bologna..., cit., págs. 43-45.

41 Eran muchos también los legados para construir nuevos altares o embellecer el de santo Domingo. Para saber más sobre el patrimonio inmobiliario dominicano, consúltense los volúmenes de V. Alce, Il convento di S. Domenico nel secolo XIII..., cit., págs. 127-174. Id., Documenti sul convento di S. Domenico..., cit., págs. 4-45; Lo scavo nel convento di S. Domenico a Bologna. Relazione preliminare, a cargo de S. Gelichi, R. Merlo, A. Di Carlo, A. Pandolfi, en «Archeologia Medievale», XII (1985), págs. 245-280.

42 R. Dondarini recuerda que, además de las donaciones y los legados, los frailes dominicos recibían los ingresos derivados de las indulgencias y de la devolución, por parte de los malechores, del dinero usurpado. En 1238, por ejemplo, el Patriarca de Aquilea concedió al prior y a la comunidad de religiosos la facultad de absolver a los usurpadores, con el fin de que dieran las ganancias obtenidas de manera incorrecta, para la construcción del convento o para las necesidades de los frailes. Archivio Conventuale di S. Domenico, C I a s. XIII, Con. N. 2, membranaceo, en V. Alce, Documenti sul convento di S. Domenico in Bologna, cit., págs. 38-39. 
sentido, la valiosa fuente del Sepultuario de $1291^{43}$ nos informa de los nombres y la ubicación de las tumbas situadas en el claustro de Santo Domingo, en la anteiglesia y en la vasta superficie dedicada a cementerio en el exterior de la iglesia, que se extendía hasta el área septentrional detrás de la sacristía. De hecho, fueron muchos los ciudadanos boloñeses, prelados, personajes ilustres ${ }^{44}$, estudiantes del Studium, que querían asegurarse la sepultura externa junto a la tumba de santo Domingo ${ }^{45}$.

A lo largo del siglo XV se mantuvo vigente la normativa que prohibía a los dominicos tener propiedades y vender bienes inmuebles, excepto en casos excepcionales, para los cuales pedían a los pontífices dispensas especiales. En los inventarios de los bienes registrados que nos han llegado dicha regla es bien evidente: las posesiones se disfrutaban en usufructo y no eran de propiedad; las de inmuebles recibidos en los legados, se destinaban al convento dominico femenino de Santa Inés. De dichos bienes, a los frailes correspondía la gestión y el resultado de los beneficios ${ }^{46}$.

$\mathrm{Si}$, por un lado, los legados testamentarios concedían el usufructo de los bienes -a los que sin embargo se añadían los gastos de mantenimiento de las casas y aquellos necesarios para registrar los actos y los documentos relativos al traspaso de la herencia-, por otro lado requerían que se recabaran de ellos las "pictancie", las limosnas y comidas que se ofrecían a los pobres en determinados días y que, por lo general, coincidían con el aniversario de la muerte del autor del testamento ${ }^{47}$.

43 S. Gelichi, R. Rinaldi, Il Sepoltuario del 1291, en Archeologia medievale a Bologna: gli scavi nel Convento di San Domenico, Bolonia, Museo arqueológico municipal, 4 de abril-31 de mayo de 1987, catálogo a cargo de S. Gelichi y R. Merlo, Casalecchio di Reno 1987, págs. 99-100. Además de esta valiosa fuente, para un análisis del patrimonio inmobiliario de los frailes predicadores consúltense los documentos del fondo estatal de santo Domingo que se encuentra en el Archivo de Estado de Bolonia y las estimaciones civiles y eclesiásticas que se conservan en el mismo Archivo.

44 Todavía hoy podemos admirar los hermosos sepulcros de los glosadores Rolandino Passeggeri y Egidio Foscarari.

45 En el interior de la iglesia hay varios casos de sepulturas extraordinarias. Entre ellas, la del hijo de Federico II, el rey Enzo.

46 No obstante, a causa de la alta crisis de mortalidad debida a las dos epidemias de peste del siglo XIV-se habla de la muerte de más de 110 frailes (Annali, pág. 404)-, los religiosos se ocuparon de comprar nuevos bienes inmobiliarios. Los inventarios de los bienes inmuebles del convento de Santo Domingo se conservan en el Archivo de Estado de Bolonia, fondo estatal de las corporaciones religiosas suprimidas. Ya a principios de los noventa del siglo XIII, el Concejo concedió aportaciones en dinero a los frailes predicadores. ASBo, Inventario generale dei fondi, Bologna 1977; ASBo, Demaniale, San Domenico. A.I. Pini, L'azienda agraria..., cit., p. 148; Id., Forme di conduzione, rendita fondiaria e rese cerealicole nel Bolognese dopo la peste del 1348: l'azienda del convento di San Domenico, en Medioevo rurale: sulle tracce della civiltà contadina, Bologna 1980, págs. 259-297.

47 El examen y la confrontación de los inventarios conservados en el fondo estatal de santo Domingo en el Archivo de Estado de Bolonia, nos permiten conocer también el destino de los terrenos agrícolas objeto de legados. Entre los principales cultivos, encontramos los de cereales mixtos con los arborícolas, con la presencia de superficies destinadas a huerto, viña o incultas que, sobre todo durante el periodo de la grave crisis económica del XIV, se acrecentaron alternándose con zonas de bosque. Las posesiones, en principio concedidas prevalentemente durante todo el siglo XIV a aparceros, fueron después, también por los cambios económicos y sociales, dados en arrendamiento. A.I. Pini, L'azienda agraria ..., cit. 
A partir de mediados del siglo $\mathrm{XV}$, el prestigio de las acciones emprendidas por los frailes predicadores en la vida comunitaria boloñesa se acrecentó aún más gracias a las consecuencias positivas de la reforma de la Orden, que se remonta a las primeras décadas del siglo, que indujo no sólo a un retorno a la regla de la Observancia de los conventos femeninos, sino también al incremento de la actividad de proselitismo por parte de los mismos frailes, que les llevó a ponerse así en competencia con las otras entidades religiosas ${ }^{48}$.

\section{El Studium de Bolonia y los Studia dominicanos: una vocación al estudio}

Tommaso Alfonsi, en un escrito suyo de 1934, afirmaba que "Bolonia es de veras la ciudad de santo Domingo"49. Como subraya Dondarini, podríamos hablar más apropiadamente de Bolonia como "una" de las ciudades de Domingo, "en la que su huella se vinculó de forma indisoluble a la de la Universidad"50.

Es indudable que la llegada de Domingo a Bolonia, el origen de la presencia de los frailes predicadores en la ciudad felsinea, su posterior enraizamiento en el tejido urbano, están estrechamente vinculados a la iniciativa y a la audacia -podríamos decir clarividencia- de Domingo de enviar a sus primeros compañeros de predicación a dos de los más importantes centros universitarios de su tiempo: a París para quien quería profundizar los estudios de Teología, y a Bolonia para quien deseaba estudiar derecho. Según el testimonio del jurista Odofredo (m. 1265), en la época de Azzone habrían estado presentes en la ciudad más de diez mil estudiantes. Un número superabundante, quizás poco creíble, pero siempre un dato que, aún fuertemente "deshinchado", atestigua la extraordinaria vivacidad de la vida del Estudio ${ }^{51}$. Gracias al jurista sabemos que el edificio en el que se desarrollaba la actividad de los legistas eran las "escuelas" de san Ambrosio (de "Scholae"=lugar donde se debatían las cuestiones públicas), sede de la casa consistorial de la época. Sucesivamente, algunos maestros se quedaron para ejercer su profesión, otros se diseminaron por otras sedes (siempre edificios eclesiásticos), otros aún ejercieron en la iglesia de San Próculo. En este intervalo que separa los

48 La iglesia de Santo Domingo fue sometida a sucesivas ampliaciones y reformas en los siglos XIVXVIII. Se edificaron numerosas capillas, un campanario y en ella trabajaron diferentes artistas. De hecho, en su interior podemos admirar un riquísimo conjunto artístico, enriquecido con las obras de Francesco Barbieri llamado "il Guercino", Nicolò dell'Arca, Jacobo Roseto, Bartolomeo Cesi, Guido Reni, Miguel Ángel Buonarroti, Nicola Pisano, Filippino Lippi, Ludovico Carracci, Alfonso Lombardi, Giuseppe Boni, y de fray Damiano Zambelli de Bérgamo, autor de las admirables taraceas de madera del monumental coro de la basilica, considerado por algunos de sus contemporáneos la "octava maravilla del mundo". Una obra que despertó la admiración del papa Clemente VII y de Carlos V, que vinieron a ver esta obra maravillosa tras la famosa coronación en San Petronio.

49 T. Alfonsi, Guida storico-artistica della Basilica di San Domenico in Bologna, Comitato provinciale del turismo, Bologna 1934 [Cita del texto original italiano traducida al castellano por Sandra Lavado Martínez].

50 Dondarins, Insediamenti dei Frati Predicatori a Bologna, cit., pág. 252 [Cita del texto original italiano traducida al castellano por Sandra Lavado Martínez].

51 N. TAMASSiA, Odofredo. Studio storico-giuridico, en ID., Scritti di storia giuridica, II, Padova 1967, págs. 385-346. 
dos momentos, se asentaron en Bolonia los predicadores de santo Domingo y aquel se convirtió en el lugar en el que se desempeñaron todas las actividades de docencia de los legistas ${ }^{52}$, la universidad de los hombres de leyes ${ }^{53}$.

Pronto, los dominicos se convirtieron en el blanco de polémicos ataques por parte de los maestros seglares, que vieron en ellos amenazadores competidores. Con la fundación de la escuela de teología de los frailes predicadores, los magistra secolorum percibieron, de hecho, la reducción de su espacio didáctico -y por consiguiente, de los ingresos que se derivaban- y la limitación del ansiado prestigio.

De algunas de las disposiciones de las "Constituciones", mencionadas antes brevemente, hemos entendido que el estudio estaba considerado como el elemento esencial para asegurar una preparación teológica adecuada a los frailes predicadores. Domingo instó reiteradamente a sus compañeros al estudio de las Sagradas Escrituras, "de tal forma que, de día y de noche, en casa o por la calle, lean o mediten siempre algo, esforzándose en retener en mente todo lo que puedan; así como a su debido tiempo deberán ser fervorosos en la predicación" 54 , y apenas tuvo ocasión les envió a estudiar teología a las dos principales universidades allende los Alpes: París y Toulouse. Por su parte en Bolonia, capital del derecho desde hacía más de un siglo, donde se enseñaba tanto el derecho civil como el derecho canónico, fue fundado un convento que se convertiría en el más importante a este lado de los Alpes, cuya historia es objeto de este ensayo.

Se decidió que cada convento debía contar desde su fundación con un profesor de teología, un lector (principalis o primarius, sucesivamente regente de los estudios), es decir, un maestro, un teólogo que pudiera enseñar a los frailes, coordinado y ayudado por un magister studentium responsable de seguir la actividad de los estudiantes. Juntos constituían el "moderatorio", o sea, el organismo encargado de la organización de la actividad escolar y del gobierno del Estudio. Por otra parte, estaba prevista la presencia de un bachiller, con funciones de vicerregente, docente de las Sentencias. Sólo el arcediano de Bolonia -a diferencia de otras ciudades italianas, en las que esta tarea se confiaba a los obispos- tenía la facultad de licenciar, es decir, de otorgar la licencia docendi ${ }^{55}$. De hecho, cada convento era una escuela de teología abierta -y pública para clérigos y laicos - a la formación de novicios pero, en general, se dirigía a todos los religiosos de la comunidad, que estaban obligados - priores incluidos- a frecuentarla.

\footnotetext{
52 Cfr. S. Cavazza, Le scuole dell'antico Studio bolognese, Milano 1896, 215.

53 En las primeras décadas del siglo XIII, se distingue entre los doctoris legis Hugolino dei Presbiteri, que encontraremos más adelante en la disertación como aquél que donó la suma de 200 liras boloñesas para la construcción del convento dominicano. Odofredo fue su alumno.

54 Lipini, San Domenico visto dai suoi contemporanei, cit., 13, pág. 235 [Cita del texto original italiano traducida al castellano por Sandra Lavado Martínez].

55 L. PaolinI, L'evoluzione di una funzione ecclesiastica: l'arcidiacono e lo Studio di Bologna nel XIII secolo, en Studi Medievali, ser. 3a, XXIX (1988), págs. 129-172; ID., La figura dell'arcidiacono nei rapporti fra lo Studio e la città, en Cultura universitaria e pubblici poteri a Bologna dal XII al XV secolo, Actas del $2^{\circ}$ Congreso (Bolonia, 20-21 de mayo de 1988), a cargo de O. Capitani, Bologna 1990, págs. 31-71.
} 
El Papa Honorio III se comprometió para favorecer la inserción, en el ámbito académico, de los frailes predicadores, definidos por él como "studentes in sacra pagina" ${ }^{56}$, con el objetivo no sólo de mejorar su nivel cultural, sino, y sobre todo, de atraer a la Orden nuevos adeptos ya preparados e idóneos para desempeñar posibles cargos. El éxito perseguido resultó confirmado por un creciente interés y deseo de los universitarios por entrar en la comunidad de los frailes predicadores haciendo propia la experiencia religiosa; así, la Orden pudo hacer alarde de una cátedra de teología en la Universidad de París. Según el estudioso Verger, al principio no hubo una voluntad por parte del papado de utilizar inmediatamente a los frailes para la enseñanza de la teología; la multiplicación de las cátedras en el siglo XIV se debió, ante todo, a la idea de difundir la cultura teológica entre los seglares gracias a las iniciativas emprendidas por los frailes mendicantes ${ }^{57}$.

Rolando de Cremona (1178 aprox.-1259 aprox.) fue el primer fraile dominico -tomó los hábitos en 1219- a quien se otorgó la cátedra universitaria de teología en 1229. El encargo fue obtenido gracias a la iniciativa de Guillermo de Auvernia, obispo de París, tras las disposiciones adoptadas para hacer frente a una huelga general de los maestros seglares. Anteriormente había estudiado y conseguido la cátedra en la facultad de las Artes de Bolonia, donde es probable que enseñara medicina. Otro magister artium, maestro licenciado en artes y letras del Estudio, fue el maestro Moneta ${ }^{58}$, conciudadano de Rolando de Cremona, ambos entre los primeros docentes dominicos de la Universidad de Bolonia junto a Claro de Sesto.

Se remonta al 17 de febrero de 1223 el documento más antiguo que menciona una escuela en el convento de San Nicolás de Bolonia: se trata de un acto de donación de un cierto Rainaldo, ex bedel del Estudio, redactado a favor de los religiosos del "apud sanctum Nicholaum in domo ubi legunt" ${ }^{59}$, por tanto, a beneficio de la "domus", la

\footnotetext{
56 Monumenta diplomatica, $\mathrm{n}^{\circ} 115$

57 J. Verger, Studia et universités, en Le scuole degli Ordini mendicanti (secoli XIII-XIV), Actas del Congreso del Centro de Estudios sobre la espiritualidad medieval, XVII, 11-14 de octubre de 1976, Todi 1978, págs. 174-203, en concreto la nota 3. Sobre la liturgia y espiritualidad dominica: J. De Cos Pérez DE Camino, La espiritualidad de Santo Domingo, fundador de la Orden de Predicadores, Salamanca 2012; B. Fueyo, En casa, fuera de casa, en el camino... Los Modos de Orar de Santo Domingo, Salamanca 2006; $\mathrm{M}$. O'CARROLL, The friars and the liturgy in the thirteenth century, en La predicazione dei frati dalla metà del '200 alla fine del '300, Actas del XXII Congreso internacional, Asís, 13-15 de octubre de 1994, Spoleto (Perugia) 1995, págs. 189-20. Sobre la producción normativa relativa a la vida litúrgico-ritual de la Orden, consúltense L. Moulin, Une Cathédrale du droit constitutionnel: l'organization dominicaine, en Le monde vivant des religieux, Paris 1964, págs. 114-132; P.A.G. Fuente, La vida litúrgica en la Orden de Predicadores. Estudio en la legislación: 1216-1980, Roma 1981.

58 Moneta de Cremona enseñó en Bolonia entre 1240 y 1250. Entre sus obras, recordamos la Summa ad versus Catharos et Valdenses (5 libros, editados en 1743), uno de los tratados más amplios y completos del siglo XIII sobre la herejía y los herejes, en defensa de la ortodoxia cristiana. Moneta había predicado varios años en Lombardia contra la herejía, y en 1228, junto a Rolando, conciudadano suyo, fundó los conventos dominicos en Cremona y después en Mantua (1233), del que fue el primer prior.

59 AFP, 42 (1972), cit., págs. 13-14.
} 
escuela de los frailes predicadores ${ }^{60}$. Es plausible considerar que en los primerísimos tiempos enseñaran en el convento algunos de los maestros de la universidad que habían entrado en la Orden; esto habría estado motivado por el hecho de que el Estudio no disponía de una sede fija propia, tanto es así que las lecciones tenían lugar en locales que los mismos docentes proporcionaban; a veces se trataba de su propia vivienda.

Habrá que esperar hasta el siglo XVI para disponer de una única sede (el palacio del Archiginnasio) donde acoger a todas las escuelas del Estudio de Bolonia y desarrollar las enseñanzas, que hasta entonces estaban desperdigadas por toda la ciudad ${ }^{61}$. En Bolonia, la sede donde se dictaban las lecciones del Estudio dominico estaba, desde sus comienzos, en una casa contigua a la iglesia de San Nicolás ${ }^{62}$.

De la elocuencia del nuevo Elías, el jurista Reginaldo de Orleáns, hemos tenido ocasión de hablar varias veces. Profesor de derecho en la Universidad de París, es probable que haya sido el primer maestro del Estudio de San Nicolás, si consideramos que fue él quien organizó el traslado de la comunidad de predicadores desde la iglesia de la Mascarella hasta la de San Nicolás de las Viñas, y que, gracias a su irresistible elocuencia, consiguió atraer a la Orden a alumnos y a profesores universitarios.

Elocuencia y arte oratorio de la predicación fueron los instrumentos que atrajeron a tantas personas a la comunidad religiosa ${ }^{63}$. Pero ¿podemos pensar que detrás de este Jacobo de Vitry, durante su breve estancia en Bolonia (1222), definió la comunidad dominicana como
una "congregatio scholarium", dedicada, sobre todo, al estudio de las escrituras y de la teología moral y
pastoral. Giacomo DA Vitry, Liber alter qui Occidentalis Historiae nomine inscribitur, en P. MANDonNet,
S. Dominique, Paris 1937, I, págs. 231-247.

Las escuelas de San Nicolás eran públicas.

${ }^{61}$ El palacio fue sede de la Universidad desde 1563 hasta 1803, cuando se mudó al Palacio Poggi. En la segunda mitad del siglo XVI, para crear un espacio abierto delante de la sede universitaria, se abrió la plaza de las Scole (la actual plaza Luigi Galvani, en cuyo centro está la estatua que representa al físico anatomista mientras efectúa experimentos con ranas). Por esa razón se derribaron varios edificios que pertenecían a la Fábrica de San Petronio - la comisión que supervisaba la construcción de la basílica homónima y que administraba los recursos económicos- con consiguiente definitiva renuncia a completar la basílica petroniana según los ambiciosos proyectos anteriores. Desde 1838 es sede de la Biblioteca municipal del Archiginnasio. Antes de la edificación del palacio del Archiginnasio, los estudiantes universitarios de derecho se reunían en Santo Domingo. La hospitalidad de los frailes es correspondida por los legistas, con la participación en la procesión en honor del santo fundador y en la fiesta de santo Tomás de Aquino. Los estatutos del 1317 establecen la fecha de la inauguración del año académico, fijada para el 10 de octubre, obviamente en Santo Domingo.

62 D'Aмато, L'origine dello studio domenicano e l'Università di Bologna, en «Sapienza», 1948: págs. 287-406; 1949: págs. 245-268.

63 Sobre la predicación de los frailes de la Orden, consúltense los siguientes textos: J. Longère, La prédication médiévale, Paris 1983; D.L. D'Avray, The preaching of the friars. Sermons diffused from Paris before 1300, Oxford 1985; De l'homélie au sermon: histoire de la prédication médiévale, a cargo de J. Hamesse, X. Herman, Louvain-La-Neuve 1993; L.-J. Bataillon, La prédication au XIIle siècle en France et en Italie, Aldershot 1993; Modern questions about medieval sermons, a cargo de N. Bériou, D.L. D'Avray, Spoleto 1994 (Biblioteca de Medioevo Latino, 11), sobre todo el ensayo introductor (D.L. D'Avray, Method in the study of Medieval Sermons, págs. 3-29); La predicazione dei frati dalla metà del '200 alla fine del '300, Actas del XXII Congreso internacional, Asís, 13-15 de octubre de 1994, Spoleto (Perugia) 1995 (en especial los textos de J. Hamesse, La prédication universitaire, L. Gaffuri, Nell'«officina» del predicatore: gli strumenti per la composizione dei sermoni latini, Letizia Pellegrini, I predicatori e i loro manoscritti, S. 
entusiasta interés se oculta una estrategia precisa acordada con la Iglesia en sus máximos niveles? Una estrategia que "se centra en una figura de maestro de derecho canónico [Reginaldo de Orleáns] mucho más acorde con el ambiente de los clérigos universitarios de lo que lo eran, al menos por lo que resulta de los documentos disponibles, los frailes presentes anteriormente en Bolonia" ${ }^{4}$. En el fondo, si reflexionamos sobre la labor de proselitismo de los primeros religiosos que se establecieron en la ciudad del derecho, hemos de reconocer un resultado desastroso, tanto que para volver a levantar el ánimo desmoralizado de aquellos frailes, fue necesaria la llegada del "nuevo Elías", Reginaldo, quien después de ni siquiera un año de permanencia en la ciudad, fue invitado a París para reclutar nuevos predicadores. Además, se advierte que las circunstancias que llevaron a la fundación y al asentamiento de una comunidad religiosa en una ciudad no estuvieron vinculadas únicamente, como pretenden muchas narraciones, a la presencia del santo fundador (a mayor razón si en la ciudad se conservan sus restos), sino que también -y llegados a este punto de nuestras observaciones, decimos sobre todo- se debieron a la decisiva intervención de la Iglesia de Roma -que quería estabilizar la presencia de los frailes predicadores en los centros urbanos- y también del mundo político local.

En Bolonia estaba Jordán de Sajonia, quien diligentemente continúa la obra de Reginaldo. Su objetivo era "hacer entrar en la órbita de la Orden figuras poseedoras de saberes universitarios que utilizar en un sistema formativo interno por construir" ${ }^{65}$, una estrategia - la de la formación de los frailes- viable gracias a la disponibilidad, desde el principio, de una amplia red de contactos ${ }^{66} \mathrm{y}$ de relaciones personales "gracias a la cual la apropiación del saber universitario tiene lugar, sobre todo, atrayendo e incorporando a los portadores de aquellos saberes". ${ }^{67}$.

Vecchio, Le prediche e l'istruzione religiosa); C.M. de La Roncière, Présence et prédication des dominicains dans le contado florentin (1280-1350), en La parole du prédicateur ( $V^{e}-X V^{e}$ siècle), a cargo de R.M. Dessì, M. Lauwers, Nice 1997 (Collection du Centre d'études médiévales de Nice, 1), págs. 363-393; The Sermon, a cargo de B.M. Kienzle,Turnhout 2000 (Typologie des sources du Moyen Âge occidental, 81-83), en especial el capítulo Medieval Preaching in Italy, págs. 449-560; B. Hodel, Edifier par la parole. La prédication de Jourdain de Saxe, maître de l'ordre des prêcheurs (1222-1237), Lyon 2002 (tesis doctoral disponible aquí: $<\mathrm{http}$ //theses.univ-lyon2.fr/documents/lyon2/2002/hodel_b - p=0\&a=top>; Preacher, Sermon and Audience in the Middle Ages, a cargo de C. Muessig, Leiden-Boston-Köln 2002 (en especial las aportaciones de C. Muessig y B.M. Kienzle).

64 R. Lambertini, Studia dei Frati Predicatori ed Università: prospettive di studio sul caso bolognese, en Domenico di Caleruega e la nascita dell'Ordine dei Frati Predicatori, cit., págs. 467-489, en part. pág. 472 [Cita del texto original italiano traducida al castellano por Sandra Lavado Martínez].

${ }_{65}$ Ibidem, p. 473 [Cita del texto original italiano traducida al castellano por Sandra Lavado Martínez].

66 M.M. Mulchahey, "First the Bow is Bent in Study". Dominican Education before 1350, Toronto 1998, págs. 27-28. Cfr. W.J. Courtenay, Academic Formation and Careers of Mendicant Friars. A Regional Approach, en Studio e studia: le scuole degli Ordini mendicanti tra XIII e XIV secolo, Actas del XXIX Congreso internacional (Asís, 11-13 de octubre de 2001), Spoleto 2002, págs. 197-217. ID., The Dominicans' Studium at Bologna and its relationship with the University in the Thirteenth Century, in Praedicatores/ Doctores. Lo Studium generale dei frati Predicatori nella cultura bolognese tra il '200 e il '300, op. cit., págs. 17-30.

67 R. Lambertini, Studia dei Frati Predicatori ed Università..., cit., pág. 474. Cfr. J. Verger, Studia et universités, en Le scuole degli Ordini mendicanti (secoli XIII-XIV), Actas de los Congresos del Centro de 
La fama que adquirió el Estudio teológico de santo Domingo en el transcurso de pocas décadas, llevó en 1246 a atribuir a la escuela boloñesa la elevación a Estudio General, categoría otorgada también a las escuelas dominicas de Colonia, Montpellier y Oxford. Se trataba por tanto de una escuela, muy similar en su organización a una facultad universitaria, y exclusiva en el campo de la teología. En efecto, si en una ciudad se encontraba un Estudio General de los frailes predicadores, no podía coexistir una análoga facultad de teología, porque ya estaba presente de manera concreta.

Además del estudio de la teología, y gracias a la incisiva promoción llevada a cabo por Alberto Magno y Tomás de Aquino, pronto se unió al currículo escolástico dominico el estudio de la filosofía. Los Studia artium, entre cuyos maestros incluimos a Rolando y a Moneta de Cremona, se implantaron en cada provincia: "La decisión del capítulo general de los dominicos va más allá de los confines de los conventos; pronto toda la Iglesia se inspirará en ella al programar los estudios del clero"68. Para comprobar que la elección llevada a cabo por Domingo fue fruto de una estrategia pensada, concebida y acordada con anterioridad con la cúpula de la Iglesia, estaba su experiencia en las zonas de la represión anticátara y los frecuentes encuentros romanos con altos prelados de la sede apostólica, entre ellos el futuro Papa Gregorio IX, el cardenal Hugolino de los Condes de Segni.

Las primeras obras de los Predicadores llegadas hasta nosotros ponen de manifiesto, por un lado, una producción de textos penitenciales destinados a la actividad pastoral y realizados por los frailes que poseían una formación canonista, y por otro, una serie de sumas teológicas conseguidas por religiosos que habían madurado una formación en el ámbito de la medicina y del arte, a la que se recurría a menudo en la enseñanza de la teología, aún cuando no hubieran conseguido el título magistral en París. Como subraya Lambertini, "en ambos casos, la Orden ha adquirido estudiantes y profesores cuyas capacidades y cuyo empeño han sido orientados con decisión hacia los fines propios de la institución religiosa a que se habían adherido; los saberes de que eran portadores no han sido de ninguna manera descuidados, sino reutilizados en el seno de un nuevo sistema formativo" $"$.

El vínculo entre la comunidad de los frailes predicadores y el universo de los legistas, titulares de las cátedras de ius civile, queda confirmado por la singular figura de Hugolino dei Presbiteri, jurista y glosador civilista, maestro de Roffredo, Odofredo y de Jacobo de Ardizzone. Él fue uno de los primeros legistas boloñeses en "acercarse a los Dominicos y en vincularse a ellos con lazos de amistad" ${ }^{\text {"70 }}$. Presente el 14 de marzo de

estudios sobre la espiritualidad medieval, XVII (11-14 de octubre de 1976), Todi 1978, págs. 175-203 [Cita del texto original italiano traducida al castellano por Sandra Lavado Martínez].

68 A. D’Aмato op., I Domenicani a Bologna, cit., I, pág.137 [Cita del texto original italiano traducida al castellano por Sandra Lavado Martínez].

69 R. Lambertini, Studia dei Frati Predicatori ed Università..., cit., pág. 489 [Cita del texto original italiano traducida al castellano por Sandra Lavado Martínez].

70 L. Loschiavo, Le scuole dei legisti all 'inizio del Duecento, en L'origine dell'Ordine dei Predicatori e l'Università di Bologna, cit., págs. 43-56. Sobre las relaciones personales entre legistas y dominicos, consúltese el ensayo de M. ConetTI, I legisti e i domenicani a Bologna tra il 1260 e il 1330. Nuove acquisizioni 
1219 en el acto con que Reginaldo de Orleáns compró el primer lote de terreno para la comunidad dominicana, aparecerá de nuevo dos años más tarde, el 7 de junio de 1221, en la compra de un nuevo lote de terreno, contribuyendo a la misma con la suma de 100 liras boloñesas ${ }^{71}$.

En 1255, Rolandino Passeggeri, jurista y maestro del arte notarial en el Estudio de Bolonia, publicó la Summa totius artis notariae: dividida en cuatro partes relativas a contratos, testamentos, actos judiciales y copias y renovaciones de actas. La obra es valiosa, ya que nos hace comprender las razones y las modalidades de la relación existente entre los frailes predicadores y los legistas ${ }^{72}$. Ya desde las primeras páginas resulta bien destacada la reverencia y la devoción hacia los frailes predicadores ("iubentibus reuerendissimis patribus et dominis meis quibusdam ex fratibus domini ordini praedicatorum quos pro communi utilitate sancta mouit affectio"'73); religiosos que son "patres" y "domini" capaces de formar y orientar ("iubere") la ciencia de Rolandino, quien compone la obra para el interés común ${ }^{74}$.

Rápidamente, muchos religiosos llegaron a Bolonia desde todos los rincones de Europa. $\mathrm{Si}$ a la muerte de Domingo los frailes podían contarse en unos trescientos predicadores, en 1237 eran casi cuatro mil y a comienzos del siglo XIV, nada más y nada menos que diez mil. Un número exorbitante que debía ser contingentado. En efecto, el Capítulo provincial de Lombardía de 1248 ordenó, de hecho, a los priores que no enviaran más novicios a Bolonia, sin una lecentia speciali del mismo prior $^{75}$. Eran cientos los conventos presentes en toda Europa, ubicados de forma predominante en ciudades episcopales, con el fin de poder colaborar con los obispos locales. Era un éxito extraordinario que se vio incrementado también por los privilegios concedidos por el papado a los frailes predicadores, a quienes se dio la posibilidad de celebrar misa públicamente en sus iglesias, así como de confesar y de acoger, tras la muerte, los cuerpos de los devotos ${ }^{76}$.

Pero es indudable que la excelente preparación cultural de los frailes y el total sometimiento y fidelidad a la Iglesia, facilitaron el ingreso de los Predicadores a los más altos cargos eclesiásticos, como sucedió en 1244 con el dominico Hugo de San Caro, que se convirtió en cardenal ${ }^{77}$.

dalle fonti dottrinali, en Praedicatores/Doctores..., op. cit., págs. 195-223 [Cita del texto original italiano traducida al castellano por Sandra Lavado Martínez].

71 La Orden de Predicadores tuvo también relaciones y contactos con la escuela de derecho de Orleáns, dado que sus magistra acostumbraban impartir lecciones en la "casa de los predicadores".

72 Summa totius artis notariae, Venetiis 1546.

73 Ibidem, f. $238 \mathrm{v}$.

74 Cfr. M. ConetTi, I legisti e i Domenicani a Bologna ..., cit., en part. las págs. 204-205.

75 AFP, 11 (1941), pág. 160.

76 Disposiciones papales que sin lugar a dudas crearon tensiones entre dominicos y el clero secular, temeroso de perder sus privilegios.

77 Son dominicos desde 1244 los obispos de Bolonia, desde 1245 los obispos de Rímini, desde 1250 los de Orvieto y desde 1255 los de Vicenza. 
Por otra parte, se recuerda que las ideas "joaquinitas ${ }^{78}$ " ejercieron una gran fascinación en dominicos y franciscanos, que "las asumieron para dar justificación históricoteológica a su nueva forma de ser y en respaldo a la ambición de ocupar una posición providencial-hegemónica en la iglesia del Cristo" "79. Una evidente consecuencia de ello, en la segunda mitad del siglo XIII, fue el enfrentamiento con los maestros seglares del Estudio parisino y la condena, como erróneas, de las ideas y posiciones adoptadas por Joaquín de Fiore. En el ámbito de la comunidad franciscana, el choque fue durísimo entre los frailes conventuales (de la "comunidad") y los frailes defensores acérrimos de la regla de San Francisco ("espirituales"), con un debate que reavivó la delicada cuestión contra la "carnalidad" ${ }^{80 "}$ de la Iglesia.

El prestigio del Estudio dominico se acrecentó aún más en la segunda mitad del siglo XIV, cuando, por dieciséis años (1387-1403), a los frailes predicadores no se les permitió la asistencia a la universidad de París. De hecho, tras el cisma que había dividido a la Iglesia y a la Orden de predicadores entre la obediencia a Aviñón y a Roma, para los frailes -que se adherían a la obediencia romana- acudir a París y estudiar allí se convirtió en algo más bien difícil y problemático. Y precisamente en esos años, el Estudio dominico tomó de hecho el lugar del de la ciudad francesa y los estudiantes y profesores fueron asignados al Estudio boloñés "pro Studio Parisiensi", manteniendo los mismos privilegios que habrían disfrutado si hubieran estado encomendados a la universidad francesa ${ }^{81}$.

Entre los más insignes personajes que han acrecentado el prestigio del Estudio, mencionamos a Juan de Legnano (muerto en Bolonia en 1383), lector de derecho del que recordamos las glosas al Decreto, a las Decretali y a las Clementine, los tratados De represaliis et de duello, De bello, sobre la censura eclesiástica y sobre el interdicto y otros varios escritos teológicos y filosóficos sobre el Cisma de Occidente, además de los consilia. Fue sepultado en Santo Domingo el 18 de febrero de 1383, junto a la sacristía. Precisamente en la iglesia de los predicadores, Juan, vicario del pontífice en Bolonia,

\footnotetext{
78 El Joaquinismo fue «sobre todo entendido como anuncio profético de una época de paz comprendida entre la persecución y la aniquilación del Anticristo y el fin del mundo: una época percibida como inminente de la que se observan las señales (malos gobernantes y corrupción de la Iglesia, discordias civiles y guerras, prodigios astronómicos y catástrofes naturales, sequía y carestías, pestilencia y muertes repentinas de personajes eminentes) y los protagonistas (el Anticristo - un tremendo tirano, un falso papa, los infieles-, el papa angélico, es decir, un pontífice santo enviado por el cielo, el emperador de los últimos tiempos)», en G.G. MerLo, Eretici ed eresie medievali, cit., pág. 73 [Cita del texto original italiano traducida al castellano por Sandra Lavado Martínez]. Cfr. R. MANSELLI, L'attesa dell'età nuova e il gioachimismo, en L'attesa dell'età nuova nella spiritualità della fine del Medioevo, 16-19 de octubre de 1960, Todi, en la Academia Tudertina, 1962, págs. 115-170 ; M.M. DufeIL, Guillaume de Saint-Amour et la polémique universitaire parisienne. 1250-1259, Paris 1972, págs. 123-126, 166-168, 172 sig. y passim; M. ReEves, The Influence of Prophecy in the Later Middle Ages. A Study in Joachimism, Oxford 1969.

79 Ibidem pág. 73 [Cita del texto original italiano traducida al castellano por Sandra Lavado Martínez].

80 Ibidem, pág. 74.

81 Mientras la comunidad de religiosos podía jactarse de un elevado prestigio dentro y fuera de la ciudad, en su seno se deterioraba cada vez más la disciplina que la reglamentaba. Es más, paradójicamente, su prestigio fue la causa -aunque no la única- del declive de su espíritu religioso.
} 
había sido condecorado por Carlos IV con el título de Conde Palatino; en la ceremonia participaron muchos maestros del Estudio y las autoridades municipales, entre ellas el potestad y los Ancianos del Concejo ${ }^{82}$.

En el siglo XVI, el Estudio dominico alcanzó su máximo prestigio, gracias también a los efectos positivos de la reforma monástica y, más en general, de la reforma de la Iglesia Católica, conocida como "Contrarreforma" a las reacciones y a las doctrinas calvinistas y luteranas de la Reforma protestante. Muchos maestros, que por formación teológica se adherían a la doctrina de santo Tomás ${ }^{83}$, participaron en el Concilio de Trento, inaugurado por el papa Pablo III en 1545 y terminado, tras diversas interrupciones, en 1563. En otras dos ocasiones, el Concilio ecuménico tuvo lugar en Bolonia, de 1547 a 1549, ya que, por temor a la peste y por escapar de las injerencias imperiales, se decidió trasladarlo a la ciudad felsinea, que era todavía el centro urbano al que los jóvenes dominicos, y no sólo éstos, se trasladaban aspirando completar sus estudios. Sin duda era un privilegio estudiar en el Estudio dominico, que fue el primero entre los Studia dell'Ordo en introducir la obligación de la "professio fidei" por parte de los lectores -según las disposiciones decididas en el Concilio Tridentino, compromiso que será introducido en toda la Orden sólo en el siglo XVII ${ }^{84}$.

82 El espléndido sepulcro de mármol que acoge sus restos es obra de Pier Paolo y Jacobello delle Masegne. Trasladado en 1478 y en 1485 por el derribo de una parte de muro sobre el que descansaba, el arca del conde palatino fue tapiada el 2 de abril 1489, con la aprobación de Juan Bentivoglio, sobre la pared del campanario, ahora visible en el Museo medieval municipal de Bolonia. Liber consil. I, f. 28 r. El monumento fue ubicado donde ahora se encuentra la memoria de Ferdinando Marsili. A Juan II Bentivoglio se deben muchas intervenciones en toda la organización urbana; en las calles y plazas, que debían adquirir una amplitud y accesibilidad hasta aquel momento obstaculizadas por el laberinto de callejuelas del centro ciudadano, destinado a adquirir un decoro digno de la gran Plaza Mayor, cuidada y embellecida para las fiestas, el palio, los carruseles, los juegos de pelota, las representaciones alegóricas y los cortejos nupciales que Juan urdía con gran maestría. 83 La filosofía de santo Tomás de Aquino constituyó el primer intento de unir los principios filosóficos aristotélicos con los del cristianismo. Análoga a la de Aristóteles, la filosofía tomista tiende a reafirmar los derechos de la razón sobre la fe, del intelecto sobre la voluntad, de la Revelación divina sobre la luz natural de la razón, dado que la filosofía y la teología son dos ciencias distintas, incluso cuando tratan los mismos argumentos. Aún así, la teología y la filosofía tienen relaciones recíprocas: la teología, con su autoridad divina de la palabra, ayuda a la razón; la razón filosófica, a su vez, respalda a la teología para demostrar algunas verdades preliminares de la misma, como por ejemplo, la existencia de Dios. De la amplísima bibliografía sobre el argumento, nos permitiremos citar sólo algunos textos básicos, siendo conscientes de que se trata más bien de sugerencias incompletas sobre una temática muy vasta; Le Ragioni del Tomismo, Milano 1979; M. C. BARTOLOMEI, Tomismo e Principio di non contraddizione, Padova 1973; I. BIfF, La teologia e un teologo. San Tommaso d'Aquino, Casale Monferrato (AL) 1984; G.K. Chesterton, Tommaso d'Aquino, Napoli 1992; M. D’Avenia, La Conoscenza per Connaturalità, Bologna 1992; C. FABRo, Introduzione a San Tommaso. La metafisica tomista e il pensiero moderno, Milano 1997; M. Forlivesi, Conoscenza e Affettività. L'Incontro con l'essere secondo Giovanni di San Tommaso, Bologna 1993; J. WeisheIPL, Tommaso d'Aquino. Vita, pensiero, opere, Milano 2003; M. PereirA, La filosofia nel Medioevo, Roma 2008; J.-P. Torrell, Amico della verità. Vita e opere di Tommaso d'Aquino, Bologna 2006; G. BARZAGHI, La Somma Teologica di San Tommaso d'Aquino, in Compendio, Bologna 2009.

84 En Bolonia, enseñaron en el Estudio dominico famosos escritores, entre los que destacamos Leandro Alberti, Crisostomo Javelli, Isidoro Isolani, Silvestro Mazzolini; muchos maestros pertenecen a las Comisiones del Santo Oficio, como el futuro papa Pío V y Alberto Drago da Riorenzuola; recordamos además (la lista es sin duda más amplia) a Ippolito Beccaria, Tommaso Zobbio, Silvestro Mazzolini da Priero y diferentes cardenales y obispos. 
A pesar de las limitaciones adoptadas para intentar frenar el número de estudiantes que frecuentaban el Estudio de santo Domingo -entre los cuales el numerus clausus de acceso al curso formal de teología; la posibilidad de asistir sólo después de haber superado el examen de admisión al mismo curso, uno o dos años en la ciudad de Bolonia, para después tener que transferirse a otro Estudio- los inscritos eran siempre muchos ${ }^{85}$.

\section{Domingo, un peregrino de viaje hacia la santidad}

En la basílica de Santo Domingo de Bolonia y en las tecas de las salas de su museo se conserva una considerable cantidad de reliquias y de valiosos receptáculos para su protección. El elevado número de sagradas prendas -se cuentan más de mil doscientas-atestigua la devoción que, durante siglos, se ha manifestado hacia el complejo dominicao. Un testimonio de fe que ha concernido ante todo a los restos del fundador de la Orden, pero también a la memoria de tantos otros santos y beatos cuyos relicarios -obras maestras de orfebrería- son documentos materiales de la búsqueda de un diseño estético merecedor y digno de la sacralidad de lo que conservan. Los inventarios de los fragmentos sagrados estudiados (desde 1390 a la reciente compulsa de 2012) y los numerosos y puntuales reconocimientos efectuados o encargados por los frailes predicadores, confirman que la devoción para con ellos se ha mantenido constante desde la Edad Media hasta nuestros días.

Del testimonio que nos dejó Fray Ventura de Verona en las Actas del Proceso de Bolonia, y con ocasión de la primera traslación de los restos mortales de Domingo, entramos en conocimiento de que "hombres y mujeres venían a su sepulcro con velas, cuadros y exvotos afirmando que Dios, por los méritos del beato Domingo, había realizado milagros a favor de ellos y de sus parientes. Es más, algunos querían recintar el sepulcro del mismo beato padre fray Domingo y recubrirlo con paños de seda, pero los frailes lo impidieron, temiendo que de la afluencia de gente la vida de la comunidad resultara perturbada y que alguien pudiera decir que eran favorables por codicia y vanagloria ${ }^{86}$ ". La devoción a Domingo se pone de manifiesto inmediatamente después de su muerte. Se trata de verdaderos peregrinajes a su tumba, o mejor dicho, a aquella fosa excavada al lado del altar mayor de la iglesia originaria de San Nicolás de las Viñas. No era necesario buscar, desportillar el suelo, como si fuera una empresa arqueológica, para encontrar los restos: en Bolonia, en una iglesia que ya existía, la auténtica reliquia de santo Domingo resultaba localizable desde el principio, inmediatamente venerable, y esta fue fundamental para la construcción de una renovada arquitectura de los espacios sagrados. El levantamiento de un nuevo edificio - o su total modernización - asumió el significado de devolver a toda el área involucrada un moderno y digno domicilio al santo.

\footnotetext{
85 Sobre las vicisitudes del Estudio teológico dominicano boloñés de los siglos XVII al XX, véase: B. Borghi, San Domenico. Un patrimonio secolare di arte, fede e cultura, Bologna 2012.

86 P. LipPini, San Domenico visto dai suoi contemporanei, Bologna 1998, pág. 449 [Cita del texto original italiano traducida al castellano por Sandra Lavado Martínez].
} 
Entre el 23 y el 24 de mayo de 1233, el cuerpo de Domingo fue exhumado y depositado en una caja de madera, y ocho días después fue colocado en un modesto y esencial sarcófago de piedra, que se puso delante de un portón, super terram de la nave menor derecha. Para acoger los restos del santo se optó de nuevo por una solución cuando menos, discutible, pero en consonancia con el carácter de la comunidad de los religiosos, que no quería ser acusada de "codicia" por la excesiva afluencia que habría causado si se hubiere colocado en sarcófago decoroso y decorado. Sin embargo, al naciente e imperioso culto al predicador Domingo, ni siquiera los frailes consiguieron oponerse, desde su formación inicial, porque la necesidad de construir un lugar sagrado para glorificar al santo fue incitada precisamente por la devoción popular, que aceleró y apremió la reelaboración de ritos complejos, cuya forma más evolucionada fue la dedicación de la iglesia. En poco tiempo, el edificio y la collación serían dedicados a "santo Domingo". La misma traslatio, es decir, la exhumación de los restos y su transporte a un lugar destinado al culto, fue la expresión de la afirmación, con nuevas exequias, de un domicilio perpetuo y adecuado para el santo.

Debido a que los hermanos -tal y como refieren los relatos de los compañeros de Domingo en las Actas del proceso de Bolonia- temían que de la tumba del santo se desprendiera mal olor, provocado por la gran cantidad de agua de lluvia confluida en el lugar del sepulcro, que había causado una depresión natural del suelo, no querían de ninguna manera que nadie ("extraños y laicos") presenciara la ceremonia de traslación de los restos. Pero, ¿cómo impedirlo? Imposible limitar y circunscribir la memoria, la devoción a Domingo. Y casi de manera consecuente, natural, nada más retirar la lápida colocada para cubrir la caja de madera, salió por el contrario un agradable olor "soave e dilettevole" ${ }^{\text {87 }}$.Todos los presentes "los obispos, los clérigos, el potestad de Bolonia y los numerosos nobles de la ciudad que habían hecho guardia ante el sepulcro, todos aseguraban haber tenido la misma sensación. El sepulcro primitivo, los objetos que se depositaban en él, como las vestiduras y las manos de aquellos que tocaron dichas cosas, quedaron impregnados de aquel aroma incluso después, durante muchos días" $"$. El culto a Domingo fue alimentado por el nutrido número de milagros atribuidos al santo después de dicho episodio. Fueron muchas las personas aquejadas de graves enfermedades que fueron curadas por "los méritos" del santo. Numerosos fueron aquellos que, como testimonio de las curaciones obtenidas, llevaban figuras de cera "que representaban los ojos, las manos, los pies y otros miembros según la diversidad de las partes del cuerpo y la multiplicidad de las curaciones obtenidas ${ }^{89}$ ". Domingo se había convertido en el mediador de la vida de la comunidad -tanto de los religiosos como de los que no lo eran-, eficaz encarnación de valores cristianos y consuelo espiritual: visitarlo significaba acudir a un lugar de prodigioso poder taumatúrgico.

\footnotetext{
87 LipPINI, cit. pág. 456.

88 Declaraciones de fray Rodolfo de Faenza, en Lippins, cit. pág. 479 [Cita del texto original italiano traducida al castellano por Sandra Lavado Martínez].

89 Lettera enciclica del 1234 del beato Giordano sulla traslazione del corpo di San Domenico, en LippinI, cit., págs. 178-179 [Cita del texto original italiano traducida al castellano por Sandra Lavado Martínez].
} 
Así, todo apuntaba hacia el proceso de canonización del santo. El reconocimiento del cuerpo incorrupto y de sus milagros dio un enérgico impulso al iter de santificación, querido por el papa Gregorio IX ${ }^{90}$ y requerido también con ahínco por las autoridades boloñesas y ciudadanas, por el clero y los frailes, que enviaron una delegación a Roma. En el siglo XII, el papa Alejandro III había reivindicado para sí el poder de reconocer la santidad de una persona y había insertado los procesos de canonización en las causae maiores Ecclesiae. Dicha norma fue confirmada por el papa Gregorio IX en 1234 y a continuación pasó a formar parte del Corpus Iuris Canonici.

Abierta una investigación oficial, el pontífice -que había conocido a Domingo y había presidido sus funerales- acogió con gran honor la petición de la delegación, nombrando, el 13 de Julio de 1233, tres funcionarios papales -fray Tomás Ubaldini de Santa María del Reno, fray Palmiro del monasterio de Campagnola y el maestro Tancredi, arcediano de Bolonia, presidente de la comisión- que tenían la misión de dar respuesta a la petición. Como postulador de la causa se eligió a fray Felipe de Verona, a partir del nombramiento del prior Vicente y del Capítulo conventual de San Nicolás de las Viñas. Así, los comisarios comenzaron a indagar sobre la vida y milagros atribuidos al fraile, recogiendo entre el 6 y el 15 de agosto de 1233 nueve textos extraídos de la comunidad de religiosos que había conocido a Domingo y con quien había convivido.

Habiendo transcurrido el fundador de la Orden mucho de su tiempo en Toulouse, los delegados apostólicos confiaron la tarea de iniciar investigaciones en el territorio del Languedoc al abad Pedro de San Saturnino, al arcediano Poncio y a Raimundo Donato.

El resumen de todos los documentos recogidos -veintisiete declaraciones francesas, refrendadas por trescientas personas, y nueve actas boloñesas, consideradas aptas para el proceso de canonización- fue enviado por el notario, previa legitimación, a Gregorio IX, que el 3 de julio de 1234, emitió la bula de santificación Fons Sapientiae ${ }^{91}$. El papa había reconocido a Domingo como santo probablemente el 29 de junio, por tanto, algunos días antes de emitir la bula, y lo había anunciado a toda la cristiandad durante su permanencia en Rieti.

\footnotetext{
90 Es conveniente recordar que el pontífice había reprendido varias veces a los frailes boloñeses por haber descuidado el culto a Domingo. Fue gracias a la insistencia de las instituciones ciudadanas y de la misma ciudad que se dio un impulso fundamental al proceso de canonización del santo fundador de la Orden.

91 Normalmente, las actas de los procesos de canonización no se conservaban. Servían para la redacción de la vida del santo. Por suerte, en nuestro caso, las cosas fueron diferentes. De hecho, nos hallamos en posesión de las Actas del proceso de Bolonia, recogidas por el notario Aldrovando, de la carta de mandato de los tres comisarios a la subcomisión de Toulouse y, por último, de la carta que estos últimos enviaron a los funcionarios boloñeses con los resultados de su investigación. De las Actas del proceso de Bolonia tenemos dos versiones: una transmitida por los códices de Venecia, Módena, Madrid y de Echard, y atribuida a Bernardo Gui, es decir, el llamado Códice de Carcassonne (escrito en tercena persona); y la otra, transmitida por Teodorico de Apolda, por Borselli, por Taegio y por Flaminio; versión trascrita probablemente de un manuscrito boloñés en primera persona. En Filippi, cit., se sigue la traducción de la edición coordinada por Walz (Acta Canozizationis S. Dominici, a cargo de R.P. Angeli Walz, MOPH XVI (1935), págs. 89-194) que había elegido como base el Códice de Venecia comparándolo con la versión de Echard. Por su parte, no se plantean problemas de interpretación de las fuentes para las actas del Proceso de Toulouse (de Languedoc), ya que los documentos que han llegado hasta nosotros básicamente concuerdan.
} 
La santidad de Domingo se sustanció en un poder que, de este modo, fue puesto al servicio del prójimo, por cuanto era "hombre de Dios", capaz de realizar milagros. Él se convirtió en santo en función de los demás y para los demás, y la comunidad se esperaba de él, mediador e integrador entre dominantes y dominados, eventos sobrenaturales.

A partir de 1267 un espléndido, rico y prestigioso sarcófago de mármol, sustentado por seis pequeñas columnas y esculpido por las magistrales manos de Nicola Pisano y de sus alumnos, se convirtió en el precioso relicario que acogió el cuerpo de santo Domingo, cuya sublimis potestas ya se ejercía en la sociedad. El santo y su culto eran la manifestación de una amplia variedad de expectativas y realidades; expresaban las necesidades y los deseos espirituales del individuo y de la toda la colectividad, deseosa de beneficiarse de sus milagros. En 1411, toda la obra escultórica de Pisano fue trasladada a una capilla construida ex profeso al lado; entre 1469 y 1473, Nicolò dell'Arca, en 1484 Miguel Ángel Buonarroti y en 1532 Alfonso Lombardi, completaron la admirable obra de arte que aún hoy podemos contemplar ${ }^{92}$.

En 1383, el cuerpo de santo Domingo fue extraído de la caja de madera y alojado en el bellísimo relicario obra del insigne orfebre boloñés Jacobo Roseto. Tras haber sido colocado en la capilla de santo Tomás, en el transepto derecho, expresamente construida para darle cabida, tras varias colocaciones diferentes, en 1950 fue ubicado detrás del arca ${ }^{93}$.

Durante las guerras mundiales se intentó salvaguardar en la medida de lo posible las reliquias y la tumba de Domingo; por ejemplo, el 17 de abril de 1943 se procedió a desmontar el arca. En dicha circunstancia, los frailes tuvieron ocasión de observar la caja de madera que desde 1473 acogía los restos del santo. Fueron fotografiados desde el pequeño orificio ubicado sobre la cubierta de la tumba. La investigación se extendió también a un minucioso examen radiográfico de los huesos, que reveló su buen estado. Entre ellos, la laringe, aún bien conservada y calcificada "señal de que él debía de estar dotado de un excelente órgano vocal, con un timbre potente como era propio de un profesional de la predicación como él había sido" ${ }^{94}$.

\footnotetext{
92 Muy útiles resultan los estudios de Joanna Cannon, del londinense Courtald Institute, que se encarga de episodios de encargos artísticos dominicanos a partir de la tesis doctoral (J. CANNON, Dominican patronage of the arts in central Italy. The provincia romana, c. 1220 - c. 1320, London 1980, 2 vols.). Se señalan en especial J. CANNon, Panem petant in signum paupertatis. The image of the quest for alms among the friars of central Italy, en Armut und Armenfürsorge in der italienischen Stadtkultur zwischen 13. und 16. Jahrhundert, a cargo de P. Helas, G. Wolf, Frankfurt am Main 2009 (Inklusion - Exklusion, 2), págs. 29-53; J. CANnon, Sources for the study of the role of art and architecture within the economy of the Mendicant convents of Central Italy. A preliminary survey, en L'economia dei conventi dei frati minori e predicatori fino alla metà del Trecento, Actas del XXXI Congreso Internacional, Asís, 9-11 de octubre de 2003, Spoleto (Perugia) 2004, págs. 215-262; J. CANNon, Dominic alter Christus? Representations of the founder in and after the "Arca di San Domenico», en Christ among the medieval Dominicans. Representations of Christ in the Texts and Images of the Order of Preachers, a cargo de K. Emery, J. Wawrykow, Notre Dame (Indiana) 1998 (Nôtre Dame Conferences in Medieval Studies), págs. 26-48.

93 V. Alce, Il reliquario del Capo di S. Domenico..., cit., págs. 3-45

94 LippinI, cit., págs. 449-450, nota 34 [Cita del texto original italiano traducida al castellano por Sandra Lavado Martínez]. Cfr. A. D’Amato, G.G. Palmieri, A. Branzi, E. Graffi-Benassi, M. Olivo, F. Frassetto, Le Reliquie di San Domenico. Storia e leggenda, ricerche scientifiche, ricostruzione fisica, Bologna 1946;
} 
Aún hoy son numerosos los fieles que llegan desde todos los rincones del mundo para contemplar las bellezas artísticas conservadas en la iglesia de Santo Domingo -en primer lugar, el arca-y para rezar sobre la tumba del santo fundador.

La amplitud del fenómeno de la peregrinación no se ha modificado con el paso del tiempo. El peregrino del siglo XXI, que ha salido curado milagrosamente de una enfermedad, expresa una consciencia de su peregrinar hacia los santuarios de una manera no muy distinta de aquella esperanza y búsqueda del fenómeno sobrenatural que condujo a los hombres en el transcurso de la historia a llegar a los lugares de culto; ayer, como hoy ${ }^{95}$.

\section{El Libellus funerarum}

En 1277, el papa Gregorio IX concedió a los frailes dominicos la facultad de poder acoger, en el área del cementerio de Santo Domingo, en el claustro y en las inmediaciones, también las sepulturas de laicos, porque eran muchas las personas que requerían encontrar reposo eterno junto al de santo Domingo ${ }^{96}$. Esto indujo a la comunidad de religiosos, al adquirir terrenos, a tener en cuenta los lugares más idóneos, alrededor de la iglesia y del convento, para extender el campo sepulcral. Por su parte, a los frailes se les reservó el camposanto ubicado detrás de la sacristía y el altar de san Lorenzo; por tanto, un área dedicada a ellos y distinta de la de los fieles. Esto no ha de sorprendernos, puesto que la misma diferenciación es representativa de una precisa repartición arquitectónica del espacio sagrado de todo el complejo monumental eclesiástico y conventual, con las dos partes en que se dividía el interior del santuario: desde la entrada hasta la altura de las capillas de santo Domingo y de la Virgen del Rosario, el espacio reservado a los laicos; la parte restante, de acceso y uso exclusivo de los frailes ${ }^{97}$.

«Bollettino di S. Domenico», XXIV (1943), págs. 67-84; XVII (1946), págs. 57-80; 83-100; LXXIV (1993), págs. 78-83; LXXVII (1996), págs. 139-148.

95 La actividad de predicación de los frailes se ha practicado siempre a lo largo del tiempo y con gran determinación. Recordemos que, en las primeras décadas del siglo XX, fueron varias las misiones fundadas en los países de América Latina por los frailes y por las monjas dominicas; entre ellas, en particular, las monjas de la beata Imelda de la Provincia de Santo Domingo. En 1937, los dominicos boloñeses fundaron una misión en Brasil. Cfr. V. Alce, Storia di una missione. Tanti anni, tante vite: una missione. Presenza domenicana in Brasile, Bologna 1987. El papel de los dominicos en la cristianización de las Américas supera los límites cronológicos de este ensayo, pero al menos véase sobre Bartolomé de las Casas, que desempeñó un papel fundamental en la reflexión sobre los derechos de los Indios, B. DE LAS CASAS, De Regia Potestate, a cargo de G. Tosi, prólogo de D. Zolo, Roma-Bari 2007 y B. DE Las CASAS, J.G. DE SePÚLVEDA, La controversia sugli indios, a cargo y con introducción de S. Di Liso, Bari 2006, que publica en italiano los textos principales de la denominada disputa de Valladolid de 1550-51, que enfrentó Juan Ginés de Sepúlveda, apologeta de los conquistadores, al fraile dominico. Muy útiles también, sobre México, S. BotTA, Religione e conquista: saggi sul discorso coloniale in Messico, Roma 2008 y, desde un punto de vista histórico-artístico, sobre el papel de la imagen en la actividad de los misioneros, S. GRuzINSKI, La colonizzazione dell'immaginario, Torino 1994 (Paris 1988).

96 Bullarium O.P., I, p. 24.

97 S. Gelichi, R. Rinaldi, Il Sepultuario del 1291, in Archeologia medievale a Bologna. Gli scavi nel Convento di San Domenico, a cargo de S. Gelichi y R. Merlo, Casalecchio di Reno (Bo) 1987, págs. 99107. Le aree cimiteriali di San Domenico a Bologna nel Medioevo (ricostruzioni topografiche), en "Atti e 
Sobre la parte izquierda de la iglesia, desde el ábside hasta el púlpito de la fachada externa, se extienden los sepulcros de los laicos. A partir del púlpito se distribuyen otras tumbas, de las que la vigésima novena de la segunda fila es la del jurista Egidio Foscarari ${ }^{98}$, que todavía hoy podemos admirar. La misma anteiglesia se utiliza como cementerio. En la primera fila, junto a la puerta de entrada, hay un espacio reservado únicamente al Concejo, con las sepulturas de los potestades ${ }^{99}$. En el interior de la iglesia y en el claustro se entierran, normalmente, las personalidades más insignes y famosas, así como los hombres de iglesia cuyas tumbas están alineadas a lo largo del muro del dormitorio, bajo el porticado $\mathrm{o}$ en el refectorio en varias filas hasta invadir el área del claustro ${ }^{100}$.

Por lo tanto, es evidente que la gestión de las sepulturas por parte de los frailes predicadores estaba estrechamente vinculada a exigencias prácticas; se trataba de un verdadero plan de organización, que implicaba una reglamentación clara, precisa y estructurada de las distintas sepulturas. Esto explica las motivaciones que llevaron a la redacción de dos inventarios de sepulturas.

Del íncipit del Libellus funerum, más conocido como "Sepultuario", venimos en conocimiento de que el texto fue redactado en 1291 por un converso de la sacristía del convento de Santo Domingo ${ }^{101}$ :

Iste est libellus funerum que sunt apud ecclesiam beati Dominici fratrum predicatorum de Bononie, editus et per lineas distinctus cum magna diligentia et investigazione a frate Johanne converso bononiensi sacristano, tempore fratris Prindipartis prioris bononiensi sub anno Domini millesimo ducentesimo nonagesimo primo $^{102}$.

memorie della Deputazione di storia patria per le province di Romagna", XLV (1994), págs. 167-229; ID., I repertori di sepolture degli ordini mendicanti, en Libro, scrittura, documento della civiltà monastica e conventuale nel basso medioevo (secoli XIII-XV), Spoleto 1999 (Actas del Congreso de Estudio, Fermo, 17-19 de septiembre de 1997), págs. 417-435; J.-L. Gaulin, Le cimitière du couvent Saint-Dominique de Bologne au XIIIème siècle, en Religion et société urbaine au Moyen Âge, études offertes à Jean-Louis Bige par ses anciens élèves, a cargo de J. Chiffoleau e P. Boucheron, Paris 2000, pág. 284, págs. 283-299. ASBo, Corporazioni religiose soppresse, San Domenico, b. 178/7512. Estas fuentes han sido utilizadas también por A. D’AмAтo, I domenicani a Bologna, Bologna 1989, I, 30, 183-90, 237-43, 445-52, 596-603; ID., I domenicani e l'Università di Bologna, Bologna 1988.

98 Sepoltuario I, ff. 17, 18. Archivio conventuale de S. Domenico III, 72900.

99 Sepoltuario I, f. 11.

${ }^{100}$ Sepoltuario I, ff. 77 sig.

101 No conocemos el nombre del autor del primer inventario, pero es posible identificarlo con un cierto Johannes familiarum fratrum predicatorum, Juan, tal vez el maestro miniaturista recordado por Filippini y Zucchini, o puede que se tratara de un copista. Lo cierto es que Juan fue un fraile de la Orden que transcribió en 1274 para la misma comunidad de religiosos el Antiguo y el Nuevo Testamento. El esmero puesto en la redacción de algunos detalles de la grafía -el Libellus funerium está compilado en escritura libraria góticaatestigua aún más la importancia del documento, que debía fijar y prever la gestión óptima de los espacios. Cfr. S. FILIPPINI, G. ZucchinI, Miniatori e pittori a Bologna. Documenti dei secoli XIII e XIV, Firenze 1947, pág. 85. De otras sepulturas se habla en distintos documentos (de 1556 a 1798) conservados en el Archivo de Santo Domingo con las siguientes referencias: 73010-73060.

102 Archivio conventuale de S. Domenico III, 72900 (I Libellus funerum), f. 1 
Se trata de uno de los dos inventarios compilados en el largo milenio llamado Edad Media, al que se han añadido e insertado sucesivas integraciones, realizadas por varias manos, entre los siglos XIV y XV; hasta llegar a comentarios del siglo XVI redactados por aquel que sería el anónimo compilador del segundo inventario, realizado entre finales del siglo XV y comienzos del $\mathrm{XVI}^{103}$.

El ordenamiento topográfico previsto en el documento, fruto de una cuidadosa inspección del área del cementerio llevada a cabo por el converso, presenta con puntual precisión cada uno de los lotes funerarios numerados y las filas en las que están colocados. De cada cuerpo se indica el nombre de pila, el patronímico, la familia de ascendencia, el lugar, la parroquia o la collación de origen ${ }^{104}$. Se trata de una planimetría de suma utilidad, de uso cotidiano; un excelente ejemplo de planificación topográfica y de parcelación de los espacios, que permite encontrar fácilmente la ubicación de los restos mortales y examinar los espacios que quedan.

El aspecto sorprendente del listado de las sepulturas inventariadas por Iohannes, o por otro copista, es el elevado número de tumbas: más de seiscientas. Un dato excepcional, si lo comparamos con la población de Bolonia, que en el siglo XIII contaba con unos 50.000 habitantes.

Es interesante observar que la redacción del Libellus funerum de 1291 parece seguir una precisa colocación de los sepulcros fruto de "una reconstrucción realista del tejido social de la época"105; una lista expositiva en consonancia con las vicisitudes que llevaron a la escena política a nuevos grupos sociales emergentes que actuaron en contacto directo con los frailes predicadores, desde la fase inicial de su asentamiento.

En la estimación ciudadana de 1296-1297 ${ }^{106}$, un cierto Johanellus quondam Petri qui facit artem vitrorum declara haber obtenido 270 liras del comercio de aceite y 400

103 Archivio conventuale di S. Domenico III, 72900 (I Libellus funerum) y 73000 (II Libellus funerum). Se revelan también interesantes los testamentos de artesanos y profesionales boloñeses redactados a lo largo del siglo XIII a favor de los frailes menores y predicadores en Bolonia. Las fuentes analizadas por la estudiosa Stefania Pirli son importantes para la localización de los primeros asentamientos ciudadanos de las nuevas Órdenes; en especial por lo que respecta al patrimonio en tierras y a las relaciones sociales de dominicos y franciscanos. S. PIRLI, Testamenti di artigiani presso le comunità cittadine di Minori e Predicatori (1230-1300), en Artigiani a Bologna. Identità, regole, lavoro (secc. XIII-XIV), en «Quaderni Dipart. Paleografia e Medievistica», ricerche e strumenti 3, a cargo de A. Campanini y R. Rinaldi, Bologna 2008, págs. 63-91. Sobre el terreno de Santo Domingo existe una serie de testamentos ordenados cronológicamente: para el periodo que analizamos, la estudiosa ha consultado los cinco sobres conservados en ASBo, Corporazioni religiose soppresse, S. Domenico, bb. 178/7512-182/7516. Existe también un repertorio de los testamentos, probablemente incompleto, redactado por los mismos predicadores entre los siglos XIII y XIV: ASBo, Corporazioni religiose soppresse, S. Domenico, 230/7564.

104 No era habitual incluir el oficio del difunto y su estatus social. Para los eclesiásticos, sin embargo, el cargo siempre viene indicado.

105 S. Gelichi, R. Rinaldi, Il Sepultuario del 1291 ..., cit., pág. 101 [Cita del texto original italiano traducida al castellano por Sandra Lavado Martínez].

106 A. I. PINI, Gli estimi cittadini di Bologna dal 1296 al 1329. Un esempio di utilizzazione: il patrimonio fondiario del boccaio Giacomo Casella, en «Studi Medievali», s. III, XVIII (1977), págs. 111-59, en la pág. 123 nota 53. Cfr. ID., Problemi demografici bolognesi nel Duecento, en «Atti e Memorie della Deputazione di Storia Patria per 1'Emilia e la Romagna», n.s. XVI-XVIII (1966-68); ID., Le riparti- 
liras en objetos de vidrio labrado; la tumba de la familia de Ciatis, aparece en nuestro "Sepultuario"107. Recordemos que, en Bolonia, lo vasos eran conocidos con el nombre "ciati" (por lo tanto, "de ciatis" del latín "cyathus) o también con el término "miuoli" (de donde "miolarus" o "de miolis) ${ }^{108}$. De manera que en Bolonia existía una intensa actividad de vidrieros, y no solo eso. A finales del siglo XIV, en la ciudad se introdujo la utilización de materias primas para el vidrio y para los hornos, lo cual confirma que existía una relativa producción local. Otras profesiones artesanales estuvieron en estrecho contacto con el convento dominico -y franciscano- con el fin de asegurarse una digna sepultura en las áreas de cementerio de los Predicadores, que se estaban extendiendo cada vez más con la adquisición de nuevos espacios. Las fuentes nos atestiguan la presencia de carniceros, barberos y otros artesanos que se querían garantizar una sepultura junto al santo español, previa solicitud ante mortem.

De hecho, tenemos noticia de un magister Petrus de Tusco Romanus, que el 24 de noviembre de 1230 donó al convento de San Nicolás de las Viñas por vía testamentaria -se trata de uno de los legados más antiguos de que tenemos conocimiento- todos los bienes de su propiedad, entre los cuales, una vivienda ubicada en la collación que se denominaba todavía "de San Nicolás", nombrando al fraile Ventura, prior del convento, apoderado de sus posesiones ${ }^{109}$.

El segundo "Sepultuario", de finales del siglo XV, es denominado "Catastro" y constituye otro ejemplo, diríamos singular y único en Bolonia, de la costumbre de marcar las sepulturas con una inscripción: una disposición, por otro lado, adoptada en Italia hacia el siglo XVIII. El documento reglamenta, aún más que el anterior libellum, las áreas de cementerio externas al claustro, aunque sin dar información sobre la orientación de las colocaciones. Este aspecto, por otro lado, se vió confirmado con el plano realizado por Gandolfi en 1789, donde las tumbas tienen disposiciones diversas ${ }^{110}$, y también diferentes espacios de ocupación del suelo. Lo cierto es que las vicisitudes de las sepulturas de Santo Domingo se presentan más bien complejas. En efecto, "queda

zioni territoriali urbane di Bologna medievale. Quartiere, contrada, borgo, morello e quartirolo, en «Quaderni Culturali Bolognesi», 1 (1977), pág. 6.

107 Sepoltuario I

108 S. Nepoti, Per una storia della produzione e del consumo del vetro a Bologna nel tardo Medioevo, en Archeologia e storia del medioevo italiano, a cargo de R. Francovich, Roma 1987, págs. 133-148 (reedición, como la que se adjunta en "il Carrobbio," IV, 1978, pp. 321-333).

109 Como ya ha sido señalado por Stefani Pirli (cit., p. 72) y por los estudios de Rossella Rinaldi (cit.), la donación de Pedro es de considerable importancia. De hecho, unos días antes del legado, tuvo lugar otra donación pro anima, realizada por Tosco a favor del prior dominico Ventura. Deja una suma de marcos y esterlinas que él mismo había recibido del mercader florentino Bunçula. Esto corrobora el interés de asegurarse, antes de su muerte, un lugar junto al santo fundador de la Orden. Cfr. V. Alce, Documenti sul convento di san Domenico, cit., pág. 22: "Ego quidem magister Petrus de Tusco Romanus [...] quas quidem res omnes et possessiones videlicet, domum quam habeo Bononie in contrata Sancti Nicholay, quam emi a Valvarino, cum omnibus aliis rebus mobilibus et immobilibus quas habeo Bononie, et libros tam decretorum et legum quam teologie, ecclesie Sancti Nicholay Predicatorum de Bononia pro anima mea relinquo $[\ldots] "$.

${ }^{110}$ H. BlaKe, Sepolture, en «Archeologia Medievale», X (1983), págs. 186-189. 
en todo caso abierto el problema de la indicación de las tumbas. Fuentes un poco sucesivas señalan, por ejemplo, la compra de cruces (¿de madera?) para el cementerio, pero de las lápidas, que sin lugar a dudas tenían que existir en este periodo, no queda rastro en el convento..."111.

En Bolonia, la presencia del cuerpo de santo Domingo reavivó, sin duda, el interés de los ciudadanos por el complejo conventual de los frailes predicadores. El libellus funerum atestigua que, setenta años después de la muerte del fundador de la Orden, eran numerosos los sepulcros que circundaban la iglesia de Santo Domingo, constriñéndola. Si bien el inventario del sacristán nos ayuda a reconstruir la topografía de la situación funeraria de aquellos años, de aquel amplio patrimonio sepulcral con tumbas incluso a

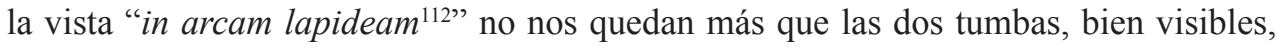
en la plaza de Santo Domingo. Un dato es cierto, como afirma Jean-Louis Gaulin: “...les usages administratifs de l'écriture -une des caractéristiques de la civilisation communale-ne s'arrêtaient pas aux portes des couvents"113.

\section{Los inventarios de las reliquias}

\subsection{Del "Liber Possessionum" de 1390 a nuestros días}

Cuando en 2012 se llevó a cabo el inventario de las reliquias presentes en Santo Domingo ${ }^{114}$, rápidamente salió a relucir la considerable importancia de los cofres sagrados que allí se conservaban. Procediendo a la numeración de los recipientes en cajas, tabernáculos, relicarios en cruz, relicarios ovalados y urnas, se ha constatado que, en el lapso de poco más de seiscientos años (desde 1390 hasta nuestros días), su cantidad se ha mantenido constante en el tiempo (inventarios 1576, 1817, 1923), con un aumento considerable en el siglo XX por motivos que, seguramente, han de achacarse al periodo bélico (para salvaguardarlas, escondiéndolas) y a la recuperación sucesiva, atestiguada precisamente por donaciones y legados de nuevos fragmentos sagrados.

Pero vayamos por orden, partiendo de algunas anotaciones sobre la historia material de las sagradas prendas - porque con toda razón las reliquias pueden ser consideradas fuentes visibles y tangibles dotadas del mismo valor que otros documentos- comenzando por las primeras noticias que tenemos de ellas.

111 S. Gelichi, R. Rinaldi, Il Sepultuario del 1291 ..., cit., pág. 104 [Cita del texto original italiano traducida al castellano por Sandra Lavado Martínez].

112 ASBo, San Domenico, 178/75512 T 79, año 1281; T 105, año 1284; T 225, año 1295.

113 J.-L. Gaulin, Le cimitière du couvent Saint-Dominique de Bologne au XIIIème siècle..., cit., pág. 284.

114 Inventario realizado por Beatrice Borghi 
En el Archivo de Estado de Bolonia se conserva el inventario más antiguo de la biblioteca del convento de Santo Domingo ${ }^{115}$. Recordado por Ludovico Frati ${ }^{116}$, el padre Franz Pelster ${ }^{117}$, Guido Zaccagnini ${ }^{118}$ y por Carlo Lucchesi ${ }^{119}$, publicado en 1943 por el medievalista y diplomatista, dominico, Marie Hyacinthe Laurent (1906-1968) ${ }^{120}$. El manuscrito, de 1390 -aunque la datación no está aceptada por todos los estudio$\operatorname{sos}^{121}$ - tal y como aparece indicado en la sobrecubierta del II Campione, fue redactado probablemente por un religioso encargado de custodiar la biblioteca. Añadimos, en nuestro caso específico con respecto al inventario de las reliquias -Liber Possessionum Conventus predicatorum de Bononia O O. Campione Secondo- casi con total seguridad de origen español, teniendo en cuenta la presencia dentro del texto de distintas muletillas típicamente ibéricas ${ }^{122}$. Datan del periodo en que fue redactado el inventario nada más y nada menos que 484 volúmenes, que incluyen los manuscritos utilizados para la lectura durante las comidas. Escritos en pergamino, excepto uno redactado "en papiro", componen un patrimonio librario que había sido organizado en 52 "bancha",

115 S. Domenico, Archivio di Stato, 240/7574, Campione II, Liber possessionum conventus Predicatorum de Bononia, f. 94r-97v. Cfr. La Biblioteca del Convento dei Domenicani in Bologna, extraído de «L'Archiginnasio», 5 (1910), págs. 1-9; L’antica libreria dei padri domenicani di Bologna alla luce del suo inventario, en «Atti e Memorie della Deputazione di storia patria per le province di Romagna», 5 (1939-40), págs. 205-252; G. Murano, I libri di uno Studium generale:l'antica libraria del convento di San Domenico di Bologna, en «Annali di Storia delle Università italiane», Volume 12 (2009). El ensayo también está disponible en http:/www.cisui.unibo.it/annali/13/testi/20Murano_frameset.htm

116 L. Frati, La Biblioteca del Convento dei Domenicani in Bologna, Extr. de «L'Archiginnasio», 5 (1910), págs. 1-9.

117 F. Pelster, Zur Ueberlieferung einiger exegetische Schriften Alberts des Grossen, Scholastik, t. 7, 1932, pág. 268

118 G. ZaCCAGnini, Le scuole e la libreria del convento di San Domenico in Bologna dalle origini al secolo XVI, «Atti e Memorie della Deputazione di storia patria per le province di Romagna», s. IV, 17 (1927), págs. 228-327y págs. 322-327.

119 C. Lucchesi, L'antica libreria dei padri domenicani di Bologna alla luce del suo inventario, «Atti e Memorie della Deputazione di storia patria per le province di Romagna», 5 (1939-40), p. 205-252. Más de un estudioso ha señalado muchas inexactitudes - tanto de contenido como en las notas- de la edición integral realizada por Lucchesi.

120 M.H. Laurent, Fabio Vigili et les bibliothèques de Bologne au debut du XVIe siècle après le ms Barb. lat. 3185, (Studi e testi, 105), Città del Vaticano 1943. Laurent se sintió obligado a reeditar un nuevo texto del Liber possessionum, ff. 95v e 97v, ante las imprecisiones detectadas en la edición realizada por Lucchesi. ${ }^{121}$ La datación de 1390 es aceptada por Frati, mientras que Zaccagnini la ubica al inicio del siglo XV, y Lucchesi la sitúa algún año antes. Por su parte, Laurent sostiene que la obra es posterior a 1371, año en que se registra en el inventario la obra Sol Christianorum de Domenico Leoni de 1371. Según Antonio Ivan Pini, el Campione se habría redactado en 1371 coincidiendo con la Descriptio del Cardenal Anglico (A.I. PINI, Campagne bolognesi. Le radici agrarie di una metropoli medievale, Firenze, 1993, págs. 145-146). Sobre la Descriptio se pude consultar la edición crítica de R. Dondarini, La "Descriptio civitatis Bononie eiusque comitatus" del cardinale Anglico (1371) $\square$, en Deputazione di storia patria per le province di Romagna, Volume 24 di «Documenti e studi», $\square$ Bologna 1990.

122 Como por ejemplo, el vocablo "oy" y otras aproximaciones de grafía determinadas por un imperfecto conocimiento de la lengua latina. El hecho de que el religioso redactor del Liber pudiera ser de origen español no ha de sorprendernos. No sólo por la evidente relación que la misma comunidad de frailes tenía que entablar necesariamente con la península ibérica, sino también porque pocos años atrás había sido fundado el Colegio de España, del que son conocidos los contactos con el convento dominicano. 
dispuestos simétricamente y según una tabla precisa de las "disciplinas": los volúmenes de derecho, de dogmática, de filosofía, de patrística, de exégesis, en el lado derecho; las obras de jurisprudencia, de teología moral, los sermones, las colecciones de exempla, alguna rara obra de historia, de hagiografía y de retórica a la izquierda. La compulsa realizada por Fabio Vigili fue consecuente a una nueva distribución de los manuscritos, a continuación de las transformaciones que sufrieron los locales de la biblioteca a lo largo del siglo XV.

Volviendo al Liber, su contenido se revela de particular interés, no sólo porque en él están registrados más de quinientos códices, sino también por las anotaciones sobre ornamentos y paramentos sacerdotales, además de la indicación de las reliquias conservadas en la sacristía del convento, que custodiaba, entre otros, varios libros antifonarios, finamente encuadernados en cuero y plata ${ }^{123}$.

En realidad no se trata de una verdadera colección de sagradas prendas, sino más bien de una lista de tabernáculos de plata, de cristal, de latón, de "magni valore" (de grandes y pequeñas dimensiones) que nos informan, la mayoría de las veces, de un genérico "muchas reliquias", y además ampollas de plata, candelabros de madera, casullas dalmáticas finamente rematadas con piedras preciosas. De algunos de los relicarios (tabernaculum) se nombran los restos de los santos, entre los que se cuentan la cabeza de santo Domingo, el dedo de san Ludovico, de san Vicente, de san Pedro Mártir, de san Alejo, de San Almerico, de San Esteban rey de Hungría. Y, además, se recuerdan personajes famosos, pertenecientes a familias boloñesas de alto rango, como algunos miembros de la familia Pepoli (Bartolomea y Juan), de la corte real de Hungría (la túnica dalmática de seda y otros complementos, el paño de terciopelo verde y rojo utilizado por la reina de Hungría). Asimismo, se mencionan las reliquias atribuidas a la Pasión de Cristo, como la madera de la cruz y sagradas prendas de la Virgen María. Se citan también algunos papas, como los pontífices Benedicto y Adriano y el emperador Constantino. Sin embargo, lo que más sorprende son los ornamentos y los objetos litúrgicos, por su cantidad y su belleza. De factura singular debía aparecer el "pannus" (una venda) bordado con unicornios, grifos y las ricas vestiduras de vivaces colores (rojo o verde) con preciadas piedras y perlas ${ }^{124}$. En el inventario hay adiciones escritas con una grafía diferente a la del autor compilador de la compulsa, que probablemente datan de finales del siglo XVIII. El redactor nos informa de que una hebilla de oro con piedras preciosas de valor es "sub pignore" a favor de Napoleón, y anota que muchas de esas piedras se cambiaron por dinero.

Desde finales del siglo XIV, con un lapso temporal de más de ciento cincuenta años, se pasa a la meticulosa inventariación de 1576 del Catálogo de las Reliquias que se encuentran en dicho año en el Relicario existente en la Iglesia de Santo Domingo de Bolonia $^{125}$.

\footnotetext{
123 Archivio Storico Italiano, Serie V, Tomo XVIII, pág. 247.

124 Se recuerda también la "lex hesdre in ebraico" que, como sabemos, será mencionada en sucesivos inventarios, hasta cuando se retuvo una copia.

125 Archivio conventuale di S. Domenico III, 76000.
} 
Sin lugar a dudas, para la historia de las reliquias y de su valor como memoria y como recuerdo de milagros, el siglo XVI fue un periodo de suma importancia y delicadeza en la afirmación del culto y en el recurso a las reliquias para respaldar la devoción popular. El decreto "Della invocazione, della venerazione e delle reliquie dei santi e delle sacre immagini", aprobado en la sesión vigésima quinta del Concilio de Trento por los obispos reunidos en diciembre de 1563, afirma que "Los santos cuerpos de los santos mártires, y de los demás que viven con Cristo, un tiempo miembros vivos de Cristo mismo...y que por Él serán resucitados para la vida eterna y glorificados, deben ser venerados por los fieles". Los restos sagrados "deben" ser devocionalmente honrados por los fieles y, por tanto, "aquellos que afirman que a las reliquias de los santos no se debe ninguna veneración y honor... han de ser condenados absolutamente, como ya desde hace tiempo la Iglesia les ha condenado y los condena todavía" 126 . Si la Reforma había propuesto, por un lado, prudencia en el reconocimiento de las reliquias y los milagros, que podía verificarse únicamente con la aprobación del obispo -una prudencia probablemente recomendada en respuesta a las posiciones de los protestantes, contrarios a su culto-, por otro lado, había inducido a la Iglesia católica a dar una enérgica respuesta ${ }^{127}$.

Respecto a las indagaciones llevadas a cabo por los frailes predicadores dominicos, que se habían basado en planes organizativos más bien improvisados y, a menudo, como de aficionados ${ }^{128}$, la Inquisición romana, instituida por Pablo III en 1542, se preparó a afrontar la herejía y a mejorar la estructuración de los procesos ${ }^{129}$.

El decreto promulgado en el Concilio de Trento atestigua que el culto de las reliquias se remontaba a los tiempos de la formación de la Iglesia Primitiva. En efecto, fueron

${ }^{126}$ Della invocazione, della venerazione e delle reliquie dei santi e delle sacre immagini, 1563. Cfr. C. Freeman, Sacre reliquie. Dalle origini del cristianesimo alla Controriforma,Torino 2012, pág. 296 [Cita del texto original italiano traducida al castellano por Sandra Lavado Martínez].

127 La Reforma invitó a cubrir los genitales de los santos, a menudo ocultos por una capa de barniz sobre la que se aplicaba una hoja de parra, así a cubrir el pecho de la Virgen María. A pesar de ello, no se pudo impedir que continuase una cierta opulencia, exaltada sobre todo con ocasión de las fiestas de los santos, también a causa de la ostentación de excesivas decoraciones en las iglesias entre los siglos XVI y XVII. Jean Baptiste Labat, en uno de sus viajes por Italia a comienzos del siglo XVIII, al visitar la iglesia de Santo Domingo en Bolonia, se lamentó: "no sé por cuál capricho, nuestros sacristanes cubren los preciosos muros de esta capilla con tapicerías en los días festivos. Es verdad que se trata de tapicería de terciopelos y de damascos cuajados de amplios entorchados de oro con ribetes y realces riquísimos, pero las taraceas y los ornamentos, tan hermosos y refinados y colocados tan a propósito, se me antojan infinitamente más adecuados que las tapicerías: en algunas ocasiones me he tomado la libertad de decirles que esas tapicerías no debían ser colgadas sino en los días de labor y para impedir que el polvo estropease ornamentos tan valiosos" JeAn Baptiste Labat, en A. Sorbelli, Bologna negli scrittori stranieri, Bologna 1927 [Cita del texto original italiano traducida al castellano por Sandra Lavado Martínez].

Para este párrafo nos referimos a la reciente edición realizada por san Ritrovato en 2007.

${ }^{128}$ Freeman, cit., pág. 296.

129 Sobre el vínculo dominicos-Inquisición, resultan fundamentales las actas de los tres seminarios: Praedicatores, Inquisitores I. The Dominicans and the Medieval Inquisition. Acts of the First International Seminar on the Dominicans and the Inquisition, 23-25 de febrero de 2002, a cargo de A. Bernal Palacios, Roma 2004; Praedicatores, Inquisitores II. Los Dominicos y la Inquisición en el mundo ibérico e hispanoamericano. Actas del segundo Seminario Internacional sobre los dominicos y la Inquisición, Sevilla 3-6 de marzo de 2004. 
los Padres de la Iglesia y los primeros "conciliares" quienes se pronunciaron a favor de la intercesión de los santos. En definitiva, se podía reanudar el antiguo camino inicial de la afirmación, ahora reafirmación, del hecho milagroso atribuido a las reliquias. El hecho es que, hasta hoy, se han efectuado periódicamente inventariaciones, con el gran esmero de compulsar las sagradas prendas y todo objeto litúrgico y de notable factura (catálogo o inventario específico de las reliquias) entre los siglos XIX y XX.

La de 1576, a pocos años de las disposiciones tridentinas, procede con el listado numerado de los tabernáculos, ostensorios, cajas, relicarios y "cuadros dorados de madera tallada colgados en la pared", con los nombres de las reliquias de santos o beatos, conservados en los receptáculos artísticos, de mayor o menor valor ${ }^{130}$, ubicados principalmente en la Capilla entonces denominada de san Jerónimo, donde estaba colocada la cabeza de santo Domingo. En total están inventariados 84 relicarios ${ }^{131}$ por un total de más de quinientos fragmentos sagrados, si bien el número es ciertamente mayor, porque a menudo, como hemos notado para el primer inventario, se utiliza la indicación "otras reliquias similares" u "otros mártires", y también, porque algunas cartelas son ilegibles ${ }^{132}$.

Son varias las reliquias atribuidas a la vida de Cristo (como fragmentos de madera de la cruz, las espinas de la corona, el paño puesto sobre su cuerpo); a la de la Virgen (sus cabellos, un velo, una piedra de su sepulcro, el manto de su marido José); a la de los apóstoles Pedro y Pablo, al protomártir Esteban (parte de la piedra usada para su flagelación); a los patronos de Bolonia (Petronio, Francisco y Floriano), a Ludovico, rey de Francia (dedo), a Santo Tomás de Aquino (índice) y al papa Pío V. Es singular la errónea atribución de un manuscrito hebreo conservado en la sacristía y considerado la historia de la reina Esther en un rollo de piel de becerro, extendida por el profeta Esdras. En realidad, se trata del Pentateuco en rollo, redactado en antiguos caracteres hebreos, que fray Amerigo Giliani de Piacenza donó en el siglo XIV a la biblioteca de Santo Domingo, junto a otras obras ${ }^{133}$.

Data del 17 de octubre de 1557 una memoria de los Annali en la que consta la noticia de la entrega de algunas reliquias por parte de Feliciano de Morbegno, prior de Viena, al archivista y guardián del sepulcro del fundador, Ludovico de Prelormo del convento de Santo Domingo ${ }^{134}$. De Prelormo nos ha llegado el registro del Libro del Arca, en la

\footnotetext{
${ }^{130}$ Los relicarios son de plata (tabernáculos y ostensorios), de madera dorada (tabernáculos, ostensorios, cajas, cuadros colgados en la pared y genéricos "relicarios") o bien de cobre (tabernáculos, "relicarios") [Cita del texto original italiano traducida al castellano por Sandra Lavado Martínez].

${ }^{131}$ En el Catalogo delle Reliquie están indicados erróneamente "84 relicarios", dado que se había omitido escribir el número 82, escribiendo dos veces el 81. Por tanto, en total, son 85.

${ }_{132}$ Al Catalogo le sigue una especie de lista manuscrita de santos en dos hojas que presenta una grafía diferente a la del inventario [Cita del texto original italiano traducida al castellano por Sandra Lavado Martínez].

133 Amerigo Giliani, a su vez, lo había recibido de algunos hebreos. V. Alce, A. D’Amato, La biblioteca di San Domenico in Bologna, Firenze 1961, p. 79.

${ }^{134}$ Las reliquias donadas se atribuyen a santa Esa Virgen y Mártir de la Compañía de S. Úrsula, patrona "singular" de Viena, a santa Úrsula, a san Segismundo rey, a san Clemente y a un fragmento del Sepulcro de san Jacobo menor. Annali, p. 863.
} 
que el guardián habla de memorias y gastos vinculados con la capilla y el monumento fúnebre homónimo. Por otra parte, en el "libro" están anotados los gastos para las velas de las lámparas de aceite utilizadas para iluminar el arca, las indulgencias acordadas a quien visitaba la tumba del santo, las obras de construcción, como la edificación de la sacristía o la "cabecera" de fray Damiano Zambelli. Al fervoroso guardián, que Supino recuerda, lamentándose, como el hábil "pulidor" que con "gestos tajantes" redondeaba la magia de los "gestos" alisados suavemente por el "soberano" cincel de Nicola Pisano ${ }^{135}$, se debe también la redacción de un inventario en que se enumeran estatuas de plata, cruces, cálices, candelabros, baldaquines, palios; en sustancia, se trata de una lista de objetos de gran valor que ya, en el 1477 habían sido anotados escrupulosamente también por su predecesor ${ }^{136}$.

En el libro di spese e di ricordi ${ }^{137}$ están anotados asimismo los días y los profusos gastos para las actividades de embellecimiento y de pulido del sepulcro marmóreo de santo Domingo. El guardián del arca pagó a los trabajadores en dinero y, deseoso de aprender las modalidades de ejecución del trabajo, donó a sus marmolistas también productos (generalmente indumentarias) para hacerlo después "et bene et optime"; como cuando, el 20 de agosto de 1548, ofreció "a maestro Francesco veronese, lustrator perfettissimo de marmori, per lustrare quelli doi angeli posti ne l'Archa, nella parte verso le finestre dove è il miracolo dil pane in mensa, lire doe et una camisa di renza acciò me insegnasse come fece..." ${ }^{138}$.

${ }_{135}$ I.B. SuPIno, Qualche ricordo di fra Ludovico da Prelormo sull'arca di S. Domenico in Bologna, Bologna 1910. G. PogGi, L'Arca di S. Domenico a Bologna, en Rosario, «Memorie Domenicane», 1909, pp. 59-67. M. Goodich, "Vita Perfecta». The ideal of sainthood in the Thirteenth Century, Stuttgart 1982 y Santi e santità nel secolo XIV, Actas del XV Congreso Internacional, Asís, 15-17 de octubre de 1987, Assisi (Perugia) 1989.

Sobre la iconografía del fundador, véanse Kaftal, L. von Matt, M.H. Vicaire, St. Dominic: A Pictorial Biography, Chicago 1957 y la tesis doctoral del mismo G. Kaftal, St. Dominic in Early Tuscan Painting, Oxford 1948. Sobre el arca de santo Domingo y su papel en la construcción del culto para el patrón, A.F. Moskowitz, Nicola Pisano's arca di san Domenico and its legacy, Philadelphia 1994 y B. Dodsworth, The Arca di san Domenico, New York 1995.

${ }^{136}$ Ludovico Prelormo, Libro dell'arca. Sobre el archivista Prelormo o Pralormo, consúltese: SuPINo, cit.;

G. ZucChin, en «Memorie domenicane» 1948, págs. 107-114.

137 Libro di Spese e di Ricordi marcado A, n. 1.

${ }^{138}$ SupINo, cit., p. 7 (c. 342). También a nuestro infatigable embellecedor de mármol le sucedió la experiencia de sentir el perfume que, según la tradición, puede olerse en la capilla del santo fundador. Y sin duda alguna, Prelormo tuvo muchas ocasiones de frecuentar el lugar. "Il primo anno che jo fra Ludovico incomentiaj atender alla S. Archa, nel meso di Marzo, un pezzo doppo el disnare, essendo in cella, mi vienne un gran sonno, et ponendomi sul thamarazzo per dormire ecco vienne il malladetto diavolo dall'inferno con una grandissima tentazione carnale. Io non feci altro dubitando di offerenda Dio mortalmente: di subbito saltai fuora del thamarazzo, mi posi il scapulario et usito fuora della celle et di subbito mi vienne una fantasia di andare alla cusina, fare scaldare un puoco de lesia e tore un puoco di sapon nero et andare a lavare il capo a una figura dil p.s. Domenico che sta inchionigione di drieto da l'Archa, quale era la più brutta e la più negra che fusse in tutta l'Archa. Adesso è la più bella, la più lustra che sia perché sempre gli ho havuto uno singolar amore, et glie ho fatto sempre più carezza che alle altre, havendogli ben ben lavato il capo, et rinfrescandolo con l'acqua di cisterna di subbito senti un odore spirare fuori de l'Archa, quale crebbe tanto vehemente che cascai sotto l'Archa: et non sapendo duove mi fusse per un gran pezzo non sapevo né 
Al maestro Andrés, escultor, el 19 de junio de 1537, con el fin de que puliera la "manita" de Cristo sujetada por la Virgen del Arca, las manos y el báculo pastoral de aquel "Obispo que está en la esquina hacia la ventana", el brazo de san Juan Bautista, las manos del papa que está situado en la parte posterior del mismo sepulcro marmóreo, Prelormo donó 4 escudos, y además, por generosidad del guardián, un escudo de oro, por un total de 3 liras, 15 sueldos ${ }^{139}$.

Se ha fechado en julio de 1558 otra donación de fragmentos sagrados realizada por obra del padre Antonino Grossutto, vicario general de la Congregación de los Predicadores en Austria, siempre a favor del convento de Santo Domingo de Bolonia ("all'Arca del Santo Padre"140). En el inventario de 1576 se cuentan todas las reliquias de los legados anteriores. La necesidad de inventariar los ornamentos litúrgicos, los objetos sagrados y de devoción, así como las reliquias, sin duda alguna está vinculada a la fuerte necesidad de preservar la memoria de un tesoro inestimable conservado en el complejo dominico; tanto es así que data del 20 de diciembre del mismo año -sólo 12 meses después de la muerte de Padre Prelormo- la memoria de algunas restauraciones a tabernáculos, en particular al relicario de la cabeza de santo Domingo, y la construcción del altar en el que se colocaron todas las reliquias y bajo el que se puso el cuerpo del beato Jacobo de Ulma, con disposiciones del Cardenal Paelotti ${ }^{141}$.

El Catalogo delle Reliquie nella Chiesa di S. Domenico ${ }^{142}$ se remonta al 10 de julio de 1817 y tiene inventariados 101 tabernáculos, para un número global de reliquias de más de quinientas cincuenta. A diferencia de las compulsas registradas con anterioridad, ésta es puntual y está bien organizada, dividida en cuatro secciones: 1) Ostensorios y tabernáculos de plata; 2) de metal; 3) plateados y dorados; 4) Ostensorios, tabernáculos y cajas de madera doradas y no doradas. Para cada uno de los receptáculos, lleva la indicación del peso, expresado en onzas y libras, por un total de 108:8 libras, equivalentes a $49 \mathrm{~kg}$. Con respecto a la catalogación realizada en el siglo XVI no se detectan grandes modificaciones, si no la adición de unos veinte relicarios (justificable si se considera el lapso temporal de más de dos siglos de distancia). Cada reliquia ha sido autenticada y colocada en su correspondiente teca, tabernáculo, caja, precintada y numerada con el

dire né far altro che piangere. Io tengo certo essere impossibile che lingua humana puotesse esprimere né la suavità, né la grandezza di tal incredibile odore”. SupINo, cit., pág. 15.

139 Ibidem, pág. 7.

${ }^{140}$ Cruz de plata con la imagen del Crucifijo y de los cuatro evangelistas, en la que se conservan varias reliquias de la madera de la Cruz y de la espina de la Corona de Cristo, de los santos Pedro y Pablo, de Andrés y Tomás apóstoles, del protomártir Esteban, de san Sebastián "y otras". Después seguirá una procesión de las reliquias para la veneración pública. Rogito Matugliani, Tom. Sagrestia. Annali, págs. 863-864. ${ }_{141}$ Annali, pág. 799. Liber consiliorum ff. 57v, 58r. D’Aмато, Le reliquie di S. Domenico, cit., págs. 59-60, 98-99. El cuerpo del beato Jacobo de Alemania (o de Ulma) fue trasladado de la capilla de santo Tomás, donde estaba sepultado, a una caja en el nuevo altar. Como de escritura de Rusticelli - Piore il P. Gio.Ma Capalla da Saluzzo.

142 «Localizadas y autenticadas con ocasión del arreglo de sus tecas y receptáculos (por la antigüedad del tiempo gastadas y estropeadas), ordenado por el Consejo Municipal en la Sesión del 18 de enero de 1816, y hecho realizar por el Jerónimo Cospi...». III. 76000. [Cita del texto original italiano traducida al castellano por Sandra Lavado Martínez]. 
número correspondiente al presente inventario y dispuesta en el "cosidetto Santuario custodito, e chiuso colle solite e distinte chiavi" en perpetua memoria.

Se remonta a 1866 un inventario "de todos los objetos que se hallan en la iglesia y sacristía de Santo Domingo en Bolonia", un precioso testimonio del esmero puesto por los frailes predicadores en conservar los valiosos fragmentos; sobre todo de las devastaciones de las que la propia iglesia, desgraciadamente, no consiguió escapar por completo, de las supresiones napoleónicas antes del fin del siglo XVIII y de las sucesivas del XIX.

Fueron también muchas las donaciones que insignes e influyentes familias boloñesas hicieron a la comunidad de religiosos y que incrementaron el número de las reliquias. Entre ellas, recordamos el legado de la familia senatorial Fibbia-Fabbri (primero del marqués Felipe Fibbia Fabbri, después de su sobrino Antonio Pallavicini Fibbia, y por último de la condesa Maria Nugent Pallavicini) que en 1888, entregó a los frailes predicadores y al prior Bonora las numerosas reliquias ("ragguardevolissima raccolta di Reliquie"143) y los muchos objetos litúrgicos que estaban en su poder.

\subsection{El inventario de 2012}

Las mismas motivaciones que incitaron a la comunidad de religiosos en el siglo XIX a tutelar y salvaguardar las sagradas prendas, a la luz de las funestas adversidades relacionadas con las supresiones y las guerras mundiales, les persuadieron a seguir en el intento con la redacción en 1923 del Catalogo delle reliquie dei Santi-Beati e Venerabili che si conservano nel Santuario interiore di S. Domenico di Bologna, sellado por el departamento administrativo del Municipio. Se trata de una lista, no de objetos con los relativos contenidos, como habían sido los anteriores, sino solamente de las reliquias de los santos ordenadas alfabéticamente, por un total de 307 sagradas prendas, seguida por la ubicación de los relicarios (101) en los diferentes estantes. Es preciso puntualizar que la compulsa es, en realidad, una copia literal del catálogo existente por duplicado en la capilla de las Reliquias, expuesto sobre las dos columnas laterales "sujeto con ganchos de hierro inamovibles y donde consta el dato de impresión del año 1743"; la mayor parte de las reliquias no han podido ser identificadas por la falta de indicaciones que podrían ayudar al reconocimiento de cada una. Por tanto, se ha procedido al exacto y escrupuloso recuento de cada una de las piezas. Cada reliquia ha sido dotada además de un número progresivo, que correspondía al número de orden de un catálogo -"quizá del Municipio"- que no se ha encontrado.

Por consiguiente, se deduce que en 1743 se llevó a cabo un ulterior inventario, anterior al de 1817 y al que siguió la copia exacta del mismo en 1923. Podríamos entonces preguntarnos si el inventario decimonónico se perdió o se ubicó en un lugar y que sólo posteriormente fue encontrado, porque es evidente que los frailes no lo conocían, dado que copiaron un catálogo más antiguo.

143 Archivio conventuale di S. Domenico, inventario III. 8355. 
En 2012 tuve el privilegio de realizar un reconocimiento de las reliquias conservadas en Santo Domingo. Señalo algunos datos, a mi juicio, sorprendentes:

- Número de relicarios: 560 receptáculos de varios tamaños, entre tabernáculos de plata, cobre y madera dorada, cajas, pequeños relicarios ovalados que contienen una o dos reliquias.

- Número de reliquias: más de 1.130 .

Los receptáculos y los fragmentos (de hueso, vestiduras, restos de gotas de sangre, de la piedra del sepulcro del santo o del mártir) están ubicados en las dos salas situadas en las plantas primera y segunda del museo, junto a la sacristía y al área conventual y son, sin lugar a dudas, algunos de los relicarios más bellos y mejor conservados, verdaderas obras maestras del arte de la orfebrería. Se encuentran en la capilla del Sagrado Corazón -donde, hasta 1950, se veneraba la cabeza de santo Domingo- en el transepto izquierdo, detrás del altar que custodia los restos del beato Jacobo de Ulma (un número considerable de reliquias dispuestas a los lados, derecho e izquierdo, y en la parte de atrás), junto a la capilla Pepoli; en la capilla de la Virgen del Rosario; en la capilla dedicada a san Pío $\mathrm{V}$, en la parte lateral derecha, en un armario empotrado sobrealzado; por último, algunos relicarios de madera dorada, en buen estado de conservación, situados en la parte alta de la cobertura del crucero de la cúpula basilical, en el lugar que se generó tras las intervenciones dieciochescas de Dotti. El relicario realizado por Jacobo Roseto, en cuyo interior se custodia la cabeza del santo fundador, está colocado detrás de su sepulcro de mármol, en la capilla del mismo nombre. Otras reliquias se encuentran diseminadas por la iglesia y el convento. Entre ellas, las conservadas en la celda de santo Domingo, como el cuchillo que se cree que perteneció al fraile y algunos fragmentos de la tabla mencionada a propósito del milagro de los panes. Se ha descubierto que detrás de la base de algunos relicarios están indicadas varias numeraciones, atribuibles al inventario de 1817, que ha sido englobado casi en su totalidad (faltan algunos tabernáculos) ${ }^{144}$. En el folleto explicativo de las salas del Museo de Santo Domingo, redactado por Alfonso D'Amato, se indica también una catalogación por obra del museo dominicano y otra realizada por iniciativa de la Superintendencia ${ }^{145}$.

Muchas de las cartelas de las parcelas son ilegibles y se ha comprobado que en el interior de las tecas hay reliquias de las que faltan sus respectivas inscripciones. Por tanto, al número de más de mil cien reliquias inventariadas podemos, sin dudarlo, añadir otras cien unidades.

\footnotetext{
${ }^{144}$ Como los tabernáculos numerados 1 y 2 y del 4 al 8 . No está presente ya desde el inventario de 1817 la biblia "autógrafa" del profeta Esdras.

${ }_{145}$ Aparecen junto a las numeraciones realizadas en 1817 y por el Museo de Santo Domingo de Alfonso D'Amato, también la compulsa de la Superintendencia con números que van del 24.798 al 25.008, que si bien no continuados, pueden incluir unas doscientas unidades.
} 
Esto sugiere que respecto a los catálogos anteriores, la cantidad de receptáculos se incrementó considerablemente - de poco más de un centenar a más de quinientos- y que las reliquias casi se duplicaron. ¿Qué ha pasado desde 1923 hasta ahora? ¿Legados, donativos, o fragmentación de las sagradas prendas con la consiguiente multiplicación de los restos?

Probablemente ambas razones. Si bien durante los dos últimos siglos, muchos objetos valiosos del patrimonio dominico han sido robados y otros dañados - de hecho, incluso obras de plata fueron fundidas por las tropas enemigas- es también cierto que el cuidado que los frailes tuvieron siempre con estos objetos les había persuadido a esconderlos también con anterioridad cada vez que se presentaba una amenaza a su integridad. Y a veces se ocultaban tan bien que volvían a encontrarse décadas, incluso siglos más tarde, ya que no siempre se guardaba memoria de sus escondites. La necesidad de conservarlos en receptáculos apropiados, confirmada asimismo por su fraccionamiento, se revela aún más en la colocación de los restos en varios lugares del complejo de Santo Domingo -en altares de nueva construcción, en paredes jamás utilizadas antes- lo cual refleja la intensidad de la devoción que tuvo que permanecer siempre viva hacia este espléndido cofre de piedra.

En el reciente reconocimiento se han encontrado más de 270 pequeños relicarios (con marcos de hoja), de cobre de factura no preciada, colocados sobre planchas de madera escondidas detrás de la capilla del Sagrado Corazón y que contienen, entre otras cosas, un fragmento de hueso y restos de las vestiduras de un santo. Nunca habían sido inventariados antes. Esto nos puede llevar a creer que se trate de nuevas adquisiciones posteriores a 1923 o de reliquias existentes fragmentadas ulteriormente; explicación creíble si se considera que muchos de los santos mencionados en las cartelas (santa Victoria, san Faustino, santa Inés, san Cándido, san Severo, san Severino, san Zamas, por poner algunos ejemplos) o relacionados con la Pasión de Cristo (de loco M. Oliveto, de domo Nazaret) se encuentran mencionados varias veces en diferentes receptáculos. También ha salido a la luz una lista de las reliquias autenticadas "in situazione" por el seminario dominico de Bolonia. Se trata de una lista de dieciocho convalidaciones, escritas a mano, que abarcan los años que van desde 1888 hasta 1909, recogidas en un marco rectangular de madera dorada, con el sello del Arzobispo de Bolonia, Cardenal Nasalli Rocca di Corneliano.

\section{Consideraciones finales}

Para concluir, volvamos al título del ensayo: una ciudad, un santo, una Orden. El complejo de Santo Domingo en Bolonia representa un lugar de acogida y, por tanto, es lugar de oración y de sabiduría. Ya desde el asentamiento de los frailes predicadores en Bolonia, es fácil vislumbrar un hilo que nos conduce inmediatamente al núcleo de una vida totalmente marcada por los tiempos de una oración continua y por la sed permanente de conocimiento. Y así, el Convento ha querido y quiere seguir siendo un 
lugar de la Iglesia y -en virtud de ello- un lugar donde hacer crecer un sentido vital de pertenencia cívica, que arquitectónicamente abraza el cuerpo del santo padre Domingo y de las numerosas reliquias allí conservadas.

Estas reliquias custodiadas en Santo Domingo dan testimonio objetivo de la devoción de todos aquellos que, durante más de ochocientos años, llegaron a Bolonia, a este complejo religioso. Las reliquias delimitan un espacio sagrado, lo enriquecen con símbolos y certezas.

Éstas han sido atesoradas siempre allí, incluso cuando las alternancias políticas y los cambios sociales trataron de limitar o de ocultar la devoción; porque son las señales más tangibles del prodigio divino, de la sacralidad de la que el devoto -el individuo o la comunidad- espera poder recibir una gracia o la oportunidad de un contacto con la santidad de un gran intercesor, como preludio y auspicio para la propia salvación.

Todas las ciudades del mundo se identifican con sus monumentos y con sus obras de arte de valor universal. En Santo Domingo, la calidad y el arte de las representaciones pintadas o esculpidas en la piedra, en el mármol, son bien visibles; su capacidad de emocionar, evocar e inspirar es todavía actual, vigorosa y consigue expresarse con renovada fuerza.

Ayer como hoy, peregrinos y viajeros. Recordar los motivos que han estimulado a muchos extranjeros a hacer un alto en Bolonia en el largo periodo de más de ochocientos años, creemos que constituye motivo de reflexión. Teniendo en cuenta que siempre hay una estrecha correspondencia entre el conocimiento de la historia y la capacidad de tutelar y apreciar sus legados, de valorizarlos en el presente y de enriquecerlos en el futuro, consideramos que precisamente de dicho conocimiento es posible volver a partir para tomar conciencia del amplio patrimonio que vivimos cotidianamente.

Traducción de italiano a castellano de $\mathrm{D}^{\mathrm{a}}$. $\mathrm{M}^{\mathrm{a}}$ del Consuelo Díez Bedmar, Universidad de Jaén. Revisión de Sandra Lavado Martínez.

Fecha de recepción: 12 septiembre 2014

Fecha de aceptación: 15 diciembre 2014 